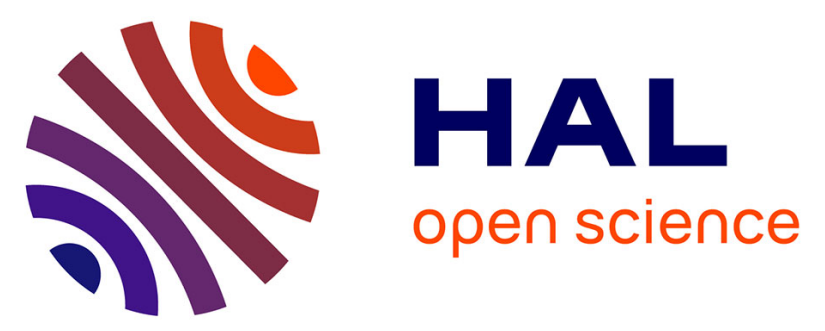

\title{
Independent Component Analysis and Parametric Approach for Source Separation in InSAR Time Series at Regional Scale: Application to the 2017-2018 Slow Slip Event in Guerrero (Mexico)
}

L. Maubant, E. Pathier, S. Daout, M. Radiguet, M.-p. Doin, E. Kazachkina, V. Kostoglodov, N. Cotte, A. Walpersdorf

\section{To cite this version:}

L. Maubant, E. Pathier, S. Daout, M. Radiguet, M.-p. Doin, et al.. Independent Component Analysis and Parametric Approach for Source Separation in InSAR Time Series at Regional Scale: Application to the 2017-2018 Slow Slip Event in Guerrero (Mexico). Journal of Geophysical Research : Solid Earth, 2020, 125 (3), 10.1029/2019JB018187 . hal-03027145

\section{HAL Id: hal-03027145 \\ https://hal.science/hal-03027145}

Submitted on 1 Mar 2022

HAL is a multi-disciplinary open access archive for the deposit and dissemination of scientific research documents, whether they are published or not. The documents may come from teaching and research institutions in France or abroad, or from public or private research centers.
L'archive ouverte pluridisciplinaire HAL, est destinée au dépôt et à la diffusion de documents scientifiques de niveau recherche, publiés ou non, émanant des établissements d'enseignement et de recherche français ou étrangers, des laboratoires publics ou privés. 


\section{JGR Solid Earth}

\author{
RESEARCH ARTICLE \\ 10.1029/2019JB018187 \\ Key Points: \\ - Two multitemporal Sentinel-1 time \\ series were constructed over the \\ 2017-2018 SSE in the Guerrero area \\ - The atmospheric delays were \\ analyzed and compared with \\ weather models and GNSS Zenithal \\ delay \\ - The SSE signal was separated from \\ atmospheric noise using ICA and \\ parametric approaches
}

Supporting Information:

- Supporting Information S1

Correspondence to:

L. Maubant,

louise.maubant@univ-grenoble-alpes.fr

Citation:

Maubant, L., Pathier, E., Daout, S., Radiguet, M., Doin, M.-P.,

Kazachkina, E., et al. (2020).

Independent component analysis and

parametric approach for source separation in InSAR time series at regional scale: Application to the 2017-2018 slow slip event in

Guerrero (Mexico). Journal of Geophysical Research: Solid Earth, 125, e2019JB018187. https://doi.org/10 1029/2019JB018187

Received 12 JUN 2019

Accepted 28 FEB 2020

Accepted article online 3 MAR 2020

\section{Independent Component Analysis and Parametric Approach for Source Separation in InSAR Time Series at Regional Scale: Application to the 2017-2018 Slow Slip Event in Guerrero (Mexico)}

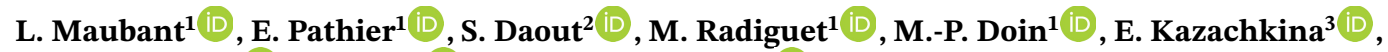 \\ V. Kostoglodov ${ }^{3}$ iD, N. Cotte $^{1}$ iD, and A. Walpersdorf ${ }^{1}$ iD \\ ${ }^{1}$ Université Grenoble Alpes, Université Savoie Mont Blanc, CNRS, IRD, IFSTTAR, ISTerre, Grenoble, France, ${ }^{2}$ COMET, \\ Department of Earth Sciences, University of Oxford, Oxford, UK, Institute of Geophysics, ${ }^{3}$ National Autonomous \\ University of Mexico, Mexico City, Mexico
}

\begin{abstract}
Separating different sources of signal in Interferometric Synthetic Aperture Radar (InSAR) studies over large areas is challenging, especially between the long-wavelength changes of atmospheric conditions and tectonic deformations, both correlated to elevation. In this study, we focus on the 2017-2018 slow slip event (SSE) in the Guerrero state (Mexico) where (1) the permanent GPS network has a low spatial density (less than 30 stations in an area of $300 \times 300 \mathrm{~km}$ ) with uneven distribution; (2) the tropospheric phase delays can be as high as $20 \mathrm{~cm}$ of apparent ground displacements, with a complex temporal evolution; (3) the tested global weather models fail to correct interferograms with enough accuracy (with residual tropospheric signal higher than the tectonic signal); and (4) the surface displacement caused by the seismic cycle shows complex interactions between seismic sequences and aseismic events. To extract the SSE signal from Sentinel-1 InSAR time series, we test two different approaches. The first (parametric method) consists of a least squares linear inversion, imposing a functional form for each deformation or atmospheric component. The second uses independent component analysis of the InSAR time series. We obtain time series maps of surface displacements along the radar line of sight associated with the SSE and validate these results with a comparison to GPS. Combining those two approaches, we propose a method to separate atmospheric delays and tectonic deformation on time series data not corrected from atmospheric delays. From the extracted ground deformation maps, we propose a first-order slip inversion model at the subduction interface during this SSE.
\end{abstract}

\section{Introduction}

At regional scale (typically larger than $250 \mathrm{~km} \times 250 \mathrm{~km}$ ), Interferometric Synthetic Aperture Radar (InSAR) is a powerful tool to get a spatially continuous measurement of the ground deformation through time with a high sensitivity to vertical displacements and without in situ measurements (e.g., Bürgmann, 2000; Simons \& Rosen, 2015). It is a good complement to the temporally dense but spatially sparse measurements from regional Global Navigation Satellite Systems (GNSS) networks. These measurements allow the deformation to be observed during all stages of the seismic cycle (e.g., Elliott et al., 2016; Floyd et al., 2016; Mackenzie et al., 2016). In spite of large data set available from recent satellite constellations like the European Sentinel-1 constellation, which provides images with return periods of 6 to 12 days, extracting transient tectonics deformation from InSAR is still challenging at regional scale. Apart from unwrapping issues linked to high surface displacement gradient or phase decorrelation (e.g., Daout et al., 2017; Doin et al., 2015), the atmospheric contribution to InSAR signal is the main source of disturbance for ground deformation measurements (Zebker et al., 1997), especially in a large study area.

The atmospheric phase screen (APS) contained in InSAR data is a combination of ionospheric signal as well as tropospheric signal. The latter can be described as a turbulent component (randomly variable in time or space) and a stratified component correlated with the topography and coherent in time (with temporal
(C)2020. American Geophysical Union. All Rights Reserved. 
seasonal variations) (Cavalié et al., 2007; Doin et al., 2009; Hanssen, 2001). The tropospheric signal is the result of spatiotemporal variations of atmospheric pressure and water vapor concentration present in the atmosphere, which modify the air refractivity and thus induce a phase delay (Hanssen, 2001). The ionospheric signal depends on the radar wavelength and is less important in C-band than in L-band. However, significant ionospheric perturbations with long-wavelength signals have been identified in Sentinel-1 interferograms (Gomba et al., 2017). The APS can dominate the InSAR signal and mask the tectonic signal (Bekaert et al., 2015a; Daout et al., 2018; Doin et al., 2009; Jolivet et al., 2011).

Therefore, the separation of the tectonic signal from the atmospheric signal contributions in InSAR data is a key challenge, and several correction approaches have been proposed. Atmospheric perturbations can be estimated empirically (Béjar-Pizarro et al., 2017; Bekaert et al., 2015; Cavalié et al., 2008; Doin et al., 2009; Lin et al., 2010; Shirzaei \& Bürgmann, 2012) by characterizing the relationship (linear or nonlinear) between the phase and the topography, or from atmospheric meteorological models (Doin et al., 2009; Jolivet et al., 2011, 2014; Yu et al., 2018). However, empirical estimation of tropospheric effects can be biased by deformation signal correlated to the topography, and global atmospheric model have limitations related to their poor spatial resolution and their uncertainties on water vapor content. Other approaches consist in using the estimations of atmospheric parameters from GPS network, like Zenithal Total Delay (ZTD) (Li et al., 2003; Williams et al., 1998) or multispectral satellite data (e.g., Li et al., 2006, 2005; Walters et al., 2013).

In addition to atmospheric delay perturbations, different sources of crustal deformation (coseismic, postseismic, and seasonal loadings) can be mixed in InSAR time series. To separate all these sources, one approach is to perform a parametric least squares regression on InSAR time series (e.g., Daout et al., 2019; Hetland et al., 2012), where the temporal evolution of each source is imposed, and its amplitude is inverted for. One important limitation arises when the temporal evolution of the source is unknown, which can be the case for atmospheric delays, seasonal loadings, or transient deformations. To overcome this problem, blind source separation approaches aim at unmixing signals without a priori information about the signal sources. Independent component analysis (ICA) (Comon, 1994; Hyvarinen \& Oja, 1997; Stone, 2004) is a classical method for blind source separation. It has the advantage over the principal component analysis (PCA) to decompose the signal in a set of statistically independent components, which are more likely to represent independent sources. ICA has been used for GPS data analysis (Gualandi \& Belardinelli, 2015; Gualandi et al., 2017) to decompose seasonal loading from other transient or earthquake signals. Recent studies have shown that ICA decomposition has been successful to analyze InSAR time series in small areas (Chaussard et al., 2017; Cohen-Waeber et al., 2018).

In this paper, we investigate different approaches to extract slow tectonic rates of surface displacements, including transient deformation, in a large-scale region where atmospheric signals are dominant. We first investigate the accuracy of global atmospheric models to correct InSAR time series. Second, we compare a parametric decomposition with an ICA approach to identify the signal of interest. We focus on the Guerrero area of the Mexican subduction zone, where large slow slip events (SSEs) occur regularly along the plate interface generating transient surface displacements at long-wavelength (hundreds of kilometers) and over several months duration. In section 2, we will present the study area and the SSEs characteristics. We then detail in section 3 the InSAR data used and the processing method to get InSAR time series for this region. In section 4, we present the parametric and ICA approaches for the decomposition of the InSAR time series, with or without correction from a global weather model. Finally, in section 5, we compare the different methods. We validate them by comparison with the GPS signal in the region and perform a first inversion of the SSE slip distribution on the plate interface.

\section{Context of the Study of SSEs in the Mexican Subduction Zone Mexico}

Continuous geodetic observations, especially GNSS, over the last two decades, have allowed to discover and characterize SSEs, which correspond to transient aseismic slip events of variable magnitudes, durations, and recurrence times. They have been identified in many subduction zones worldwide like Cascadia, New Zealand, and Japan (Beroza \& Ide, 2011; Schwartz \& Rokosky, 2007). These SSEs correspond to transient shear slip events that occur along the plate interface of subduction zone, generally in regions downdip or adjacent to the so-called locked patches, where large thrust earthquakes occur (e.g., Obara \& Hirose, 2006; Rousset et al., 2017; Wallace et al., 2018). Associated with these SSEs activities tremors and low frequencies earthquakes have been detected, as it is the case for the Japan, Cascadia, Mexico, and the New Zealand 
subduction zones (Bartlow et al., 2014; Frank et al., 2015; Husker et al., 2019; Obara \& Hirose, 2006; Rogers \& Dragert, 2003; Villafuerte \& Cruz-Atienza, 2017). Precise assessment of the spatial extension of slip at depth during SSEs, as well as understanding the possible interactions between SSEs and seismic rupture is important for a better understanding of the impact of those events on the seismic cycle and remains an important challenge. Due to their sparsity and uneven distribution, GNSS stations are not always sufficient to correctly measure surface deformation associated with SSEs. InSAR measurements represent a complementary tool, which could enhance the spatial coverage of measurements (Bekaert et al., 2016). Since the launches of Sentinel-1 satellites, temporal recurrence of image acquisition (6 to 12 days) has greatly increased, and it thus became possible to investigate the temporal variations of transient signal with InSAR time series (e.g., Rousset et al., 2016).

Along the Mexican subduction zone, in the Guerrero region, long-term SSEs of equivalent magnitude around Mw 7.5, among the largest worldwide, occur with a recurrence time of about 4 years, with durations between 6 to 14 months (Kostoglodov et al., 2003; Radiguet et al., 2012). These SSEs produce surface displacements up to $5 \mathrm{~cm}$ on the horizontal (southward) and up to $3 \mathrm{~cm}$ on the vertical components (Radiguet et al., 2012) (Figure 1). The first event observed using GPS was in 1998 (Lowry et al., 2001), and since then successive SSEs have occurred in 2001-2002 (Kostoglodov et al., 2003; Larson et al., 2004), 2006 (Larson et al., 2007; Radiguet et al., 2011; Vergnolle et al., 2010), 2009-2010 (Walpersdorf et al., 2011), and 2014 (Gualandi et al., 2017; Radiguet et al., 2016). In this region, two types of interactions between SSE and earthquakes were previously observed. On one hand, the triggering of the 2010 SSE and associated tremors by a large distant earthquake (Maule Mw 8.8) has been suggested (Walpersdorf et al., 2011; Zigone et al., 2012). On the other hand, the spatiotemporal proximity between the 2014 SSE occurrence and the Mw 7.3 Papanoa earthquake hypocenter (UNAM Seismology Group, 2015) suggests the triggering of the thrust event by the ongoing SSE (Radiguet et al., 2016).

The last SSE of the region, which began in May 2017 and ended in June 2018, occurred during the period of intense seismic activity in the region. In September 2017, two large intraslab earthquakes take place, in Chiapas area (Mw 8.1, 07 September 2017) and in Puebla state (Mw 7.2, 19 September 2017) (Figure 1a) (Melgar, Pérez-Campos, et al., 2018; Melgar, Ruiz-Angulo, et al., 2018; Mirwald et al., 2019; Segou \& Parsons, 2018; Suárez et al., 2019). In February 2018, an interface thrust earthquake occurred in Oaxaca state (Pinotepa earthquake, Mw 7.1, 16 February 2018). GPS observations in the region (Figure 1b) show a possible impact of the earthquake occurrence on the SSE evolution, as after the September 2017 seismic sequence, some GPS stations, like the TCPN station, show a change in slope corresponding to a deceleration of the SSE (Figure 1b).

In this study, we investigate the spatiotemporal characteristics of the 2017-2018 SSE in Guerrero, using InSAR in order to enhance the spatial coverage in this region where the GPS network is unevenly distributed causing data gaps like in the Tierra Caliente region (Figure 1a). Two previous studies analyzed the 2006 SSE with InSAR (Bekaert et al., 2015; Cavalié et al., 2013), the main difficulty in these studies was the correction of the atmospheric signal, with amplitudes up to $20 \mathrm{~cm}$ and partly controlled by two topographic barriers: the southern border of the Mexican Plateau and the Sierra Madre del Sur (Figure 1a). The second issue is that the long-wavelength SSE signal is correlated to the topography. The presence of vegetation is another difficulty, as it reduces the InSAR coherence.

\section{InSAR Data and Processing}

We use Sentinel-1 (ESA) TOPSAR data in interferometric wide-swath mode (swath width of about $250 \mathrm{~km}$ ) between January 2016 and August 2018, with acquisitions separated by 6 days to 1.5 months. Two tracks have been processed (Figure 1a) spanning from the coast to the TMVB (Trans-Mexican Volcanic Belt), one $450 \mathrm{~km}$ long swath in ascending orbit (A078) and another $330 \mathrm{~km}$ long swath in descending orbit (D041). We choose not to process the data acquired before 2016 for two reasons. First, the time span between successive acquisitions was longer (24 days) before 2016 than after (12 days), resulting in poorer InSAR coherence. Second, the Papanoa earthquake (18 April 2014 Mw 7.3; Radiguet et al., 2016; UNAM Seismology Group, 2015) has a long postseismic signal (at least until the end of 2015) that complicates the time series analysis. For the ascending data, acquisitions are missing between 08 August and 25 September 2017, resulting in a data gap during the initial stage of the SSE before the Mw 8.1 and 7.2 earthquakes. We use, respectively, 90 and 67 acquisitions for the descending and ascending tracks to create a short baseline interferometric network 

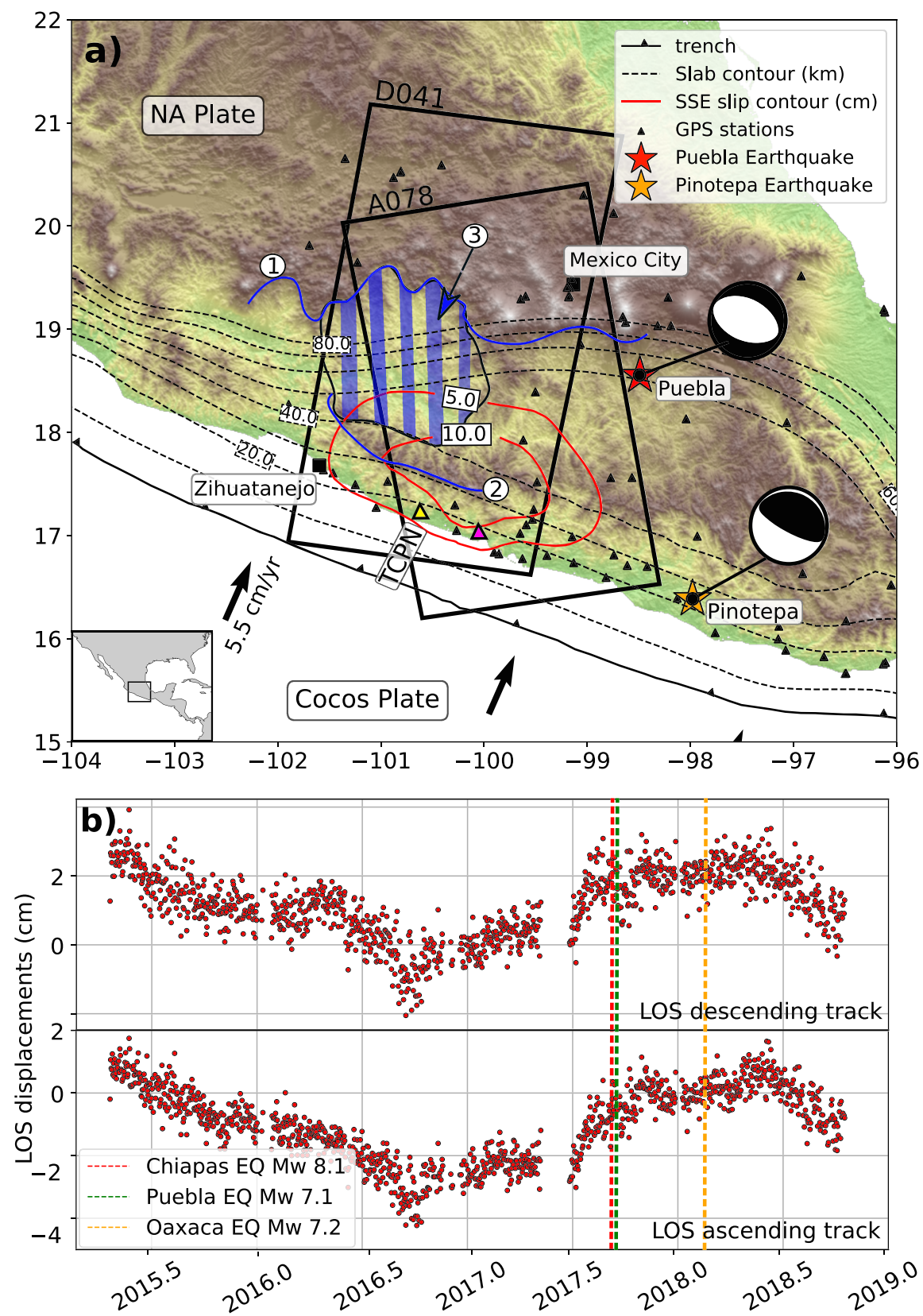

Figure 1. (a) Setting of the Mexican subduction zone around the Guerrero area and location of InSAR and GPS data coverage. The black rectangles represent the coverage of the two InSAR tracks processed in this study. The black arrows indicate the convergence velocities of the Cocos plate with respect to the North America Plate from the PVEL model (DeMets et al., 2010). The black line with triangles represents the Middle American Trench (MAT). Black dashed lines are isodepths (interval of $10 \mathrm{~km}$ ) of the subduction interface. Red lines are the 5 and $10 \mathrm{~cm}$ slip contours of the average of the last three SSEs (2006, 2009-2010, and 2014) occurring on the subduction interface (Radiguet et al., 2012, 2016). The triangles represent the GPS stations (UNAM, IGF, SSN, and TLALOCNet), the yellow and pink filled triangles show the position of TCPN and CAYA GPS stations, respectively. The stars represent the epicenters of Puebla earthquake in red (17 September 2017) and of Pinotepa earthquake in orange (16 February 2018). The blue lines are the topographic barriers (1: Trans-Mexican Volcanic Belt (TMVB), 2: Sierra Madre del Sure (SMdS)). The hatched region (3) represents the Tierra Caliente depression. (b) Example of times series of surface displacements along two different radar lines of sight (top: for descending track D041, bottom for ascending track A078) reconstructed from a time series of TCPN GPS station (yellow triangle on map) between 2015 to October 2018. The timing of the three earthquakes are displaying by dashed vertical lines. 
with, respectively, 624 and 431 selected pairs (Figure S1 in the supporting information). We invert those two networks into two independent time series (one for the descending track and one for the ascending), using the New Small Baselines Subset processing chain (Doin et al., 2011; Grandin, 2017), which is based on the ROI_PAC software (Rosen et al., 2004). We provide below some specifications of the data processing strategy.

Once the stack of coregistered interferograms is created (with a spatial resolution reduced by multilooking with two looks in range and eight looks in azimuth) and corrected using an implementation of the enhanced spectral diversity method (Grandin, 2015), the first challenge is to unwrap them. The difficulty arises from the combination of two effects: (1) low coherence in mountains and vegetated areas, especially during summer months and for long interferograms duration, and (2) narrow fringes due to strong atmospheric delays, particularly along steep topography relief. In order to facilitate unwrapping, we use four main procedures: (1) We select in priority the interferograms with better coherence than the average or with limited atmospheric patterns including a few 1 year apart winter-winter pairs (Figure S1), (2) we remove tropospheric delays correlated to the topography (Figure 1a) and spatial ramps before unwrapping, (3) we multilook to 16 looks in azimuth and $4 \times 16$ in range (620 m pixel spacing) and filter the interferograms (the filter is a weighted average of the gradient of the phase in sliding windows), and (4) we check possible unwrapping errors using network adjustment (López-Quiroz et al., 2009). For step (2) we first tested, for a few dates, the correction from ERA-Interim predictions (Doin et al., 2009; Jolivet et al., 2011). However, we decide to not use this correction because we noticed that for numerous corrected interferograms, the fringe gradient was not significantly decreased and sometimes even increased because of inaccuracy of ERA-Interim model. Instead, we estimate, on each wrapped interferogram, an empirical relation between the wrapped phase and the elevation (e.g., Doin et al., 2015; Grandin et al., 2012). To do that, we begin to search the local linear ratio in subwindows $(15 \mathrm{~km} \times 15 \mathrm{~km})$ between the phase and the elevation. These ratios are fitted by the following equation:

$$
\phi(z, y)=(a+b * y) * \frac{\left(z-z_{\text {ref }}\right)^{2}}{2}+(c+d * y) * \frac{\left(z-z_{\text {ref }}\right)^{3}}{3}
$$

where $\phi$ is the interferometric phase $a, b, c$, and $d$ are adjusted parameters evaluated by calculating the relation between the phase and the altitude, $z$ is the local altitude, $z_{\text {ref }}(8,000 \mathrm{~m})$ is the altitude where we assume the convergence of phase delays, and $y$ is the azimuth coordinate. Inconsistencies of parameters ( $a$, $b, c$, and $d$ ) are detected and then reestimated by least squares network adjustment. Then equation (1) is used to correct interferograms with the reestimated parameters. Similarly, in order to flatten the interferogram before unwrapping as much as possible, a linear ramp in range and a quadratic ramp in azimuth are estimated on wrapped interferograms, inverted on the interferograms network, before being used to correct the interferograms.

In the Step 3, the corrected interferograms are multilooked and filtered with a weighting based on colinearity, a modified estimate of coherence, which does not take into account the radar backscatter (Pinel-Puysségur et al., 2012). In natural environment, variations of amplitudes are indeed uncorrelated with the variance of the phase, and it is, therefore, better to not take into account the amplitude as weighting in coherence measurements. We choose to apply a filter with a sliding window of 12 pixels, on which the complex phase is averaged taking into account the local phase gradient. Then the data are filtered and unwrapped as done by Doin et al. (2015). Unwrapping proceeds spatially with a path based on the coherence associated to the filtering step (Grandin et al., 2012). Some remaining unwrapping errors affecting large patches can be identified by visual checking and corrected by imposing the unwrapping path (López-Quiroz et al., 2009). Once unwrapped, we finally reintroduce all previously removed corrections (ramp and atmospheric) to each interferogram to reconstruct the full unwrapped phase signal. The purpose of these corrections was not to separate the source of the signals but to flatten the interferogram to help for unwrapping. Indeed, those corrections estimated on wrapped phase are possibly less accurate than those done on unwrapped phase and may contain some tectonic signals, which is why they are reintroduced. An estimation of the orbital ramps (linear in range and azimuth) is then applied on the less noisy and continuous unwrapped interferograms and adjusted to be consistent within the interferometric network before performing the time series analysis. The phase of the unwrapped interferograms is referenced with respect to a common area where we expect more phase stability, which is the northern part of the track covering the TMVB (see extent in Figure S3). Finally, interferograms are inverted into time series that allows us to detect corresponding remaining unwrapping errors in the interferometric network. If necessary, the processing is then iterated again from the unwrapping step by imposing by hand the right wrapping paths of faulty interferograms. 
We construct a phase time series using the New Small Baselines Subset method (Doin et al., 2015; López-Quiroz et al., 2009) relative to the first date.

$$
\phi_{i}=\phi_{\text {def }}+A P S+\phi_{\text {error }}
$$

The phase time series $\phi_{i}$ is a mix of contributions from surface displacement, $\phi_{d e f}$, and from the atmosphere, APS, and $\phi_{\text {error }}$, which contain the orbital errors and DEM errors; $\phi_{\text {def }}$ includes at least a linear term and transient term related to SSE. Once the time series is created, we estimate a spatial linear ramp per date as a function of azimuth and range for each acquisition epoch and set to 0 the average phase delay in the nondeforming area, helping to flatten and refer cumulative displacement maps to a common area. All these processes are done in radar geometry, before geocoding. The next challenge consists now in separating the atmospheric signal from tectonic deformation.

\section{Signals Decomposition}

Once the InSAR time series have been obtained, we intend to extract the tectonic signal despite the fact that the atmospheric contribution is dominant. We are looking for a method that can be applied in most of the active tectonic areas and at regional scale. We first investigate the benefit of using a global weather model to estimate the tropospheric contribution in the InSAR signal by comparing the prediction of existing global weather models to GPS-ZTD (Zenital Total Delay) data. At regional scale, it is rather common in active tectonic areas to have, at least, a few permanent GPS stations available from which time series of ZTD can be estimated. The comparison between global weather models and observed ZTD helps us to validate the model. Then, the objective is to see what is the gain for our source separation approaches of using tropospheric correction of InSAR time series based on global weather model or ZTD measurements. For this purpose, two different data sets are produced: InSAR time series corrected from a global weather model and InSAR time series without any tropospheric correction. On these two data sets we will test two different approaches of source separation: the parametric decomposition and the ICA.

\subsection{Tropospheric Correction Using External Data}

In a first step, we test the corrections of our time series using two global atmospheric models with different spatial resolutions: the ERA-Interim model (grid with spatial resolution of $0.75^{\circ}$ and a time interval of $6 \mathrm{hr}$ ) and the HRES-ECMWF model interpolated by GACOS (Yu et al., 2018) with a grid resolution of 0.125 and a time interval of $6 \mathrm{hr}$ ). Note that these GACOS data were not including GPS measurements at the time we downloaded them from the GACOS website. The acquisition hour of our SAR data is similar to the calculation hour of the different models ( $00 \mathrm{hr}$ for the ascending and $12 \mathrm{hr}$ for the descending track). For simplicity, we hereafter refer to these models as ERA-I and GACOS. For each acquisition date, we map the vertical profiles predicted by ERA-I or GACOS along the radar line of sight (LOS) and compute the phase delay at each pixel elevation in radar geometry. In addition, we extract the ZTD obtained from the GPS stations located inside the footprint of the radar images, at the time of each SAR acquisitions. For each station, the values of the ZTD are reprojected in LOS. We will call these data reprojected GPS-TD $L_{O S}$. ZTD provide a direct estimate of the temporal evolution of the atmospheric effects in the region of interest, and can be compared with the temporal evolution of the two global weather models along the radar LOS.

For the 21 GPS stations considered in the descending track area, all the GPS-TD $L_{O S}$ time series show similar temporal evolutions (Figure 2d). The dispersion depends mainly on the altitude and the latitude of the stations. To compare the temporal evolution of global weather models and of GPS-TD $L_{O S}$, we perform a PCA on all three data sets to extract the common signal. For GPS-TD $L_{O S}$, ERA-I, and GACOS models, the first principal component (PC1) accounts for $98 \%, 89 \%$, and $88 \%$ of the data variance, respectively. The PC1 amplitude comparison is displayed in Figures $2 \mathrm{a}$ and $2 \mathrm{~b}$, whereas the temporal evolutions are shown in Figure 2c. The temporal evolution is coherent between the three PC1 (Figure 2c). The dominant signal in the InSAR time series is the tropospheric signal (Figure 2e). It is relative in time and space, and coherent with the topography, which makes it more difficult to extract and the global weather models seem to underestimate the amplitude of this signal. The amplitude and the sign of the tropospheric delays will therefore depend of the reference point. Concerning the amplitudes of $\mathrm{PC} 1$, both models show limitations in reproducing the amplitude of phase delay extracted from GPS-TD $L_{O S}$ (Figures 2a, 2b, and S2c). ERA-Interim shows its main limitation at high altitude (higher than $1,800 \mathrm{~m}$ ), on the Mexican Plateau, and close to the coast where the 

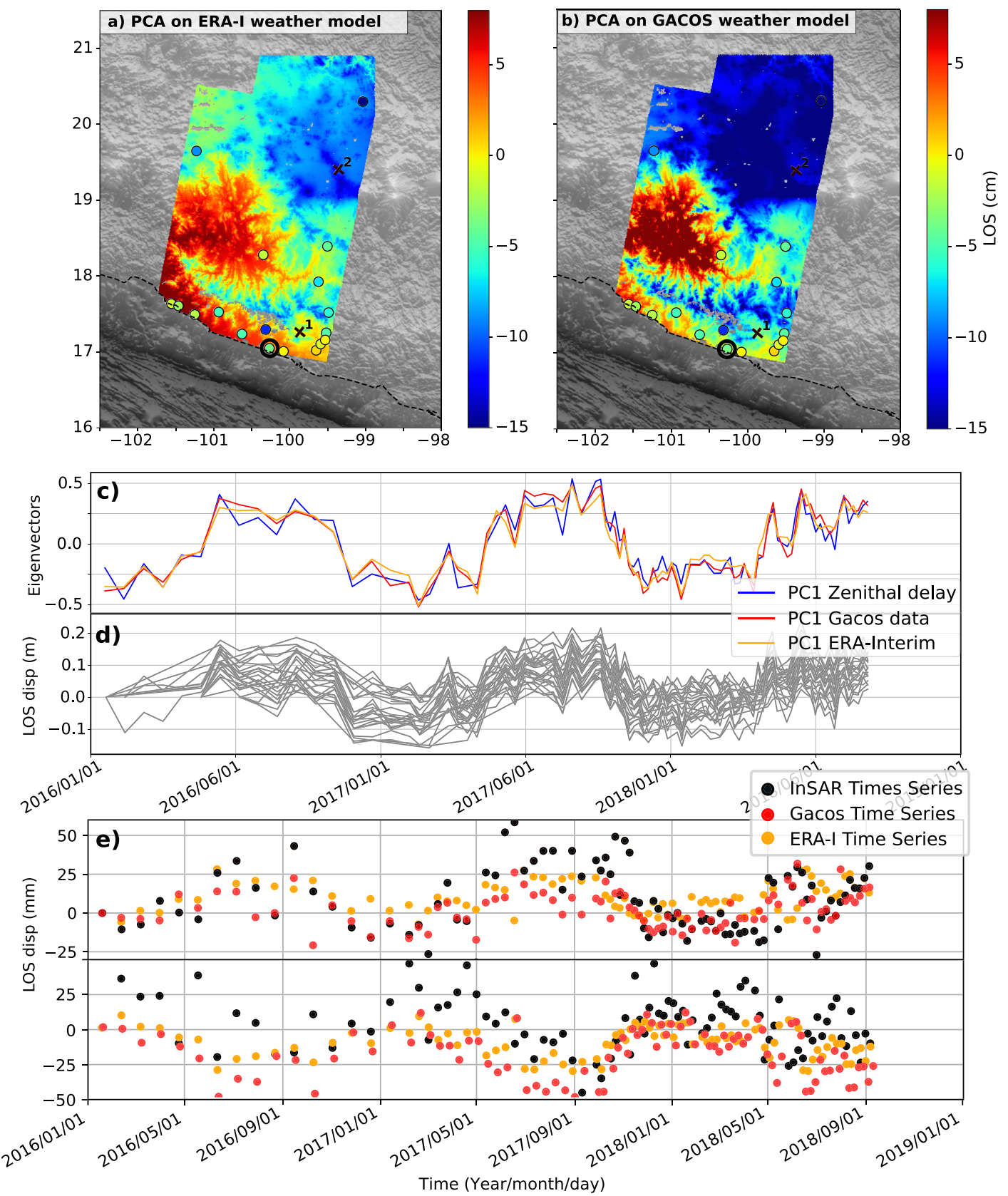

Figure 2. Comparison of LOS phase delay from global weather model and GPS-TD $L_{O S}$ using PCA. (a) Amplitude map of the first component of the principal component decomposition of ERA-I delay maps in centimeters along LOS (referenced relative to the CAYA location, black circle); the colored circles represent the amplitude of the zenithal delay (convert along LOS of the satellite) relative to CAYA station in centimeters. Black crosses give locations of pixel for time series in plot e. (b) Same as (a) but for the GACOS delay maps. (c) The blue line is the temporal evolution of the first component of the TDL $L_{O S}$ from GPS data present in the footprint of the track, extracted with a PCA. Red: the first component of GACOS model. Orange: the first component of ERA-Interim. (d) Temporal evolution of GPS-TD $L_{O S}$ for 21 stations located in the footprint of the InSAR tracks, relative to the first date. (e) In black, phase temporal evolution ( $\mathrm{mm}$ ) of two pixels of the InSAR time series (Crosses 1 and 2 in the plot a) referenced to the first date, and the comparison with GACOS (red dots) and ERA-I (orange dots) time series. Up: time series for pixel 1, located in the SSE area. Down: time series or Pixel 2, located in the Mexican Plateau, where the tectonic signal is expected to be smaller. 
tectonic signal is expected (Figures 2a and S2a). The GACOS model seems to be able to reproduced better the spatial variability of the tropospheric delay (Figures $2 b$ and S2b). Overall the GACOS model looks better than the ERA-I, in agreement with a previous study from Murray et al. (2019). Consequently, in the following, we will only test corrections of the InSAR time series with the GACOS model.

For the decompositions performed in the following part, we consider two data sets: the first one is the InSAR time series previously computed with equation (2), and corrected from spatial ramps, and the second one is the same time series but with an additional correction from the GACOS weather model.

\subsection{Parametric Decomposition}

In the Guerrero area, during the period 2016-2018, the surface deformation signal we would like to separate from tropospheric signal in our InSAR time series, mainly consists into an linear trend (called inter-SSE), and a slow-slip event (SSE) signal. To extract the inter-SSE long-wavelength surface displacement rate from our time series and the map of the first-order spatial pattern of the SSE, we perform a parametric decomposition of our time series. The temporal evolution of each component is imposed, and we invert the amplitude of each basis function. We decompose temporally the time series for each pixel, considering two tectonic contributions (inter-SSE and SSE), and an atmospheric signal (for the data set not corrected from GACOS). Based on the signal observed on GPS surface displacement time series (Kazachkina et al., 2018), we model a two phases SSE (one phase before the September 2017 earthquakes and a second after, see Figure $1 \mathrm{~b}$ and section 2). Each pixel can thus be described as

$$
\phi_{(t)}=a * t+b * A P S(t)+\frac{C_{1}}{2}\left(\tanh \left(\frac{t-T_{1}}{\tau_{1}}\right)+1\right)+\frac{C_{2}}{2}\left(\tanh \left(\frac{t-T_{2}}{\tau_{2}}\right)+1\right)+d
$$

where $t$ is the time and $a, b, C_{1}, C_{2}$, and $d$ correspond, respectively, to the amplitudes of the linear term, the seasonal tropospheric signal, the first and second phases of the SSE and a constant. To represent the seasonal tropospheric term $A P S(t)$, we take the normalized eigenvector of the first principal component estimated from the GPS-TD $L_{O S}$ time series (Figure 2c). This signal contains most of the temporal variations present on the tropospheric signal, as it explains $98 \%$ of the GPS-TD $L_{O S}$. For the data set that is already corrected from GACOS, we suppress the APS term in equation (3). Following Larson et al. (2004), the SSE is modeled with two tangent hyperbolic functions that represent the two phases of the event and allow to model the observe change in slope in the time series (Figure 1c). With this approach, we suppose that the beginning and the end of the SSE are the same for all pixels of the tracks, which means that there is no migration during one phase of the SSE. However, a migration can be taken into account by combining between two phases of the SSE. The temporal scaling $\left(\tau_{1}, \tau_{2}\right)$ and median time $\left(T_{1}, T_{2}\right)$ of the two phases are imposed based on observation of GPS time series in the region (Kazachkina et al., 2018). We determine the $2 \tau$ value from which $76 \%$ of the surface displacement is produced. We impose $T_{1}=2,017.5$ ( $1 \mathrm{July} 2017$ ), with $\tau_{1}=0.25$ ( 3 months): Thus, the first phase began in May 2017 and finished in September 2017. For the second phase, we impose $T_{2}=2018.1$ and $\tau_{2}=0.3$ (from the end of September 2017 to April 2018).

For each SSE phase, we obtain an amplitude map of the surface displacement (Figures S4 and S7), which we sum up to produce the cumulative map of the SSE amplitude (Figure 3, without GACOS correction, and Figure S3a, with GACOS correction). This amplitude modulates the temporal evolution associated to each function in equation (3), it must not be confused with the radar amplitude. Additionally, we obtain an amplitude map for the inter-SSE trend (Figure 3c) and the atmospheric signals (Figure S6b). We also calculate the residual map between the data and the parametric model (Figures $3 \mathrm{~b}$ and $3 \mathrm{~d}$ ) using equation (4) to compute the residual for each pixel.

$$
R M S E=\sqrt{\frac{\sum_{t=1}^{N}\left(\phi_{\text {data }}(t)-\phi_{\text {model }}(t)\right)^{2}}{N}}
$$

where $N$ is the number of acquisition dates and $\phi_{\text {model }}$ is the result of the parametrized decomposition.

Let us first describe the amplitude map of the SSE for the descending track D041. As the horizontal displacements related to SSE in the Guerrero region are almost parallel to the descending track, InSAR measurements for D041 are expected to be mainly sensitive to the vertical displacement of the SSE. The amplitude map of the SSE (Figure 3) shows an uplift pattern well located on the Sierra Madre del Sur (Figure 1a) as well as a subsidence pattern north of this area, as already shown by previous studies (Bekaert et al., 2015; Cavalié et al., 2013). The maximum amplitude for the SSE is $4 \mathrm{~cm}$ for the two data sets 

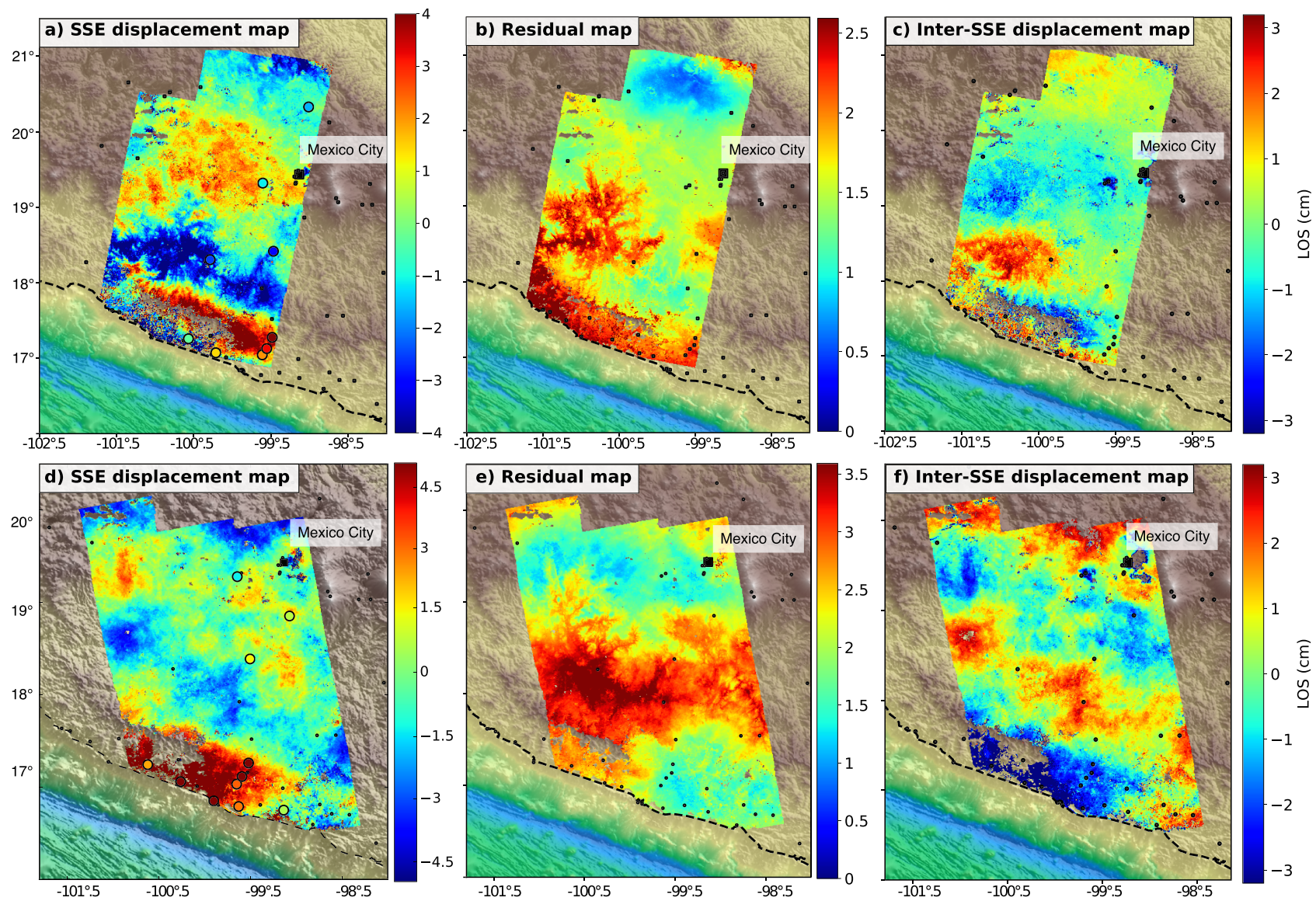

Figure 3. LOS surface displacement of the 2017-2018 SSE estimated from parametric method for descending (top row) and ascending (bottom row) tracks (without prior global weather model corrections). (a and d) Amplitude map of the SSE in centimeters along LOS calculated with the parametric method. Colored dot show the same amplitude but estimated from GPS displacements time series. (b and e) Residual map of the time series. (c and f) Inter-SSE displacement map. The small black points represent the location of GPS stations; the dashed line represents the coast limitation.

(not corrected or corrected with GACOS, Figures 3a and S3a). Regarding the residual maps associated with each data set (Figures $3 \mathrm{~b}$ and S3b), we observe residuals that are reduced by $20 \%$ for the noncorrected data set compared with the data set corrected from GACOS, especially in areas where they are large variation of topography (e.g., bottom of the valleys and volcanoes), like in the Tierra Caliente region. This observation suggests that GACOS weather model is less efficient at capturing the seasonal signal than a parametric estimation of the atmospheric delay based on GPS-TD $L_{O S}$ (APS term in equation (3)). Using GACOS correction and no parametrization of the atmospheric term introduces a larger dispersion of the residual time series induce and therefore a higher error in the estimation of the amplitude of the SSE. We obtain a better fit for the time series data set not corrected from global weather models and decomposed with the GPS-TDL $L_{O S}$ vector. We therefore apply this approach based on ZTD measurements for the ascending track, with results shown in Figures 3d and S6 and S7. For this track, we observe a spatial pattern similar to the descending track in the Sierra Madre del Sur (with a displacement toward satellite). In both tracks, the amplitude map of the inter-SSE term (Figures S6 and S8) is opposite to the SSE map. Although this result is expected in the Guerrero region where inter-SSE and SSE with surface displacement of opposite signs alternate (e.g., Cavalié et al., 2013), it is also observed in the northern part of the track, which suggests a trade-off between the SSE and inter-SSE parameters. This trade-off can be due to the fact that in our InSAR time series the main period without SSE is quite short (about 1 year before the SSE) and with less frequent data acquisitions than during the SSE period. We expect this trade-off to be reduced when longer InSAR time series will be processed in the future. The amplitude map of the GPS-TD $L_{O S}$ term is clearly correlated to the topography (Figures S6 and S8). The comparison of the amplitude maps of the two phases of the SSE (Figures S4 and S7) suggests a possible migration toward the east of the event. Reconstruction of the temporal evolution 
using these two terms $\left(C_{1}\right.$ and $C_{2}$ in equation (3)) also suggests a migration of the event in the eastern part of Guerrero (Figure S5).

To conclude, in the Guerrero area, the parametric decomposition applied here is able to separate the first-order seasonal tropospheric signal from the inter-SSE trend and the SSE signal, with consistent results in ascending and descending tracks. It also provides uncertainties associated with each of these components. However, the main limitation is that this method depends on the imposed parameterization, which requires some a priori knowledge and assumptions. In this particular case, the SSE is parameterized using two subevents of fixed timing and duration. GPS observations suggest that timing and duration of the SSE have some variations depending on the GPS station location due to the SSE migration (Kazachkina et al., 2018), which can bias our parameterization. Moreover, with this approach, we are limited to analyzing transients of already known duration using independent measurements such as GPS. To go further a nonlinear exploration of the SSE timing could be implemented. In the following, we explore an ICA decomposition on the detrended time series of surface displacements.

\subsection{ICA Decomposition}

\subsubsection{Method}

The ICA method has the potential to overcome some of the limitations of the previous method, because as it allows the signal to be decomposed without any assumptions. The statistical independence is assumed by considering that each component has a non-Gaussian probability distribution and that the sum of each non-Gaussian component tends toward a Gaussian distribution (Hyvarinen et al., 2004). The InSAR data matrix $\mathrm{X}$ is assumed to be described by the following equation:

$$
X_{(t * p)}=A_{(t * n)} \cdot S_{(n * p)}
$$

where $A$ is the mixing matrix and $S$ is the matrix of independents components, $n$ is the number of independent components considered, $p$ the number of pixels, and $t$ the number of dates. We are performing here a temporal ICA, where we are searching for temporally independent sources as in Gualandi and Belardinelli (2015).

ICA algorithms are more effective on detrended data sets (Gualandi \& Belardinelli, 2015). Removing a linear trend in the time series reduces the correlation between the different sources and improves the decomposition of the data. Although the removal of a temporal linear trend may help to separate the SSE signal from other sources, this term corresponds in our case to the inter-SSE signal and implies a prior estimation of it before the decomposition. To be consistent with the parametric approach previously presented, so that the SSE amplitudes obtained using the two methods can be compared, we use the InSAR time series of surface displacements, corrected from the same long-wavelength spatial ramps and the inter-SSE linear trend obtained from the parametric decomposition (Figures S6a and S8a). This step requires an a priori knowledge of the beginning and end of the SSE. However, the trend estimate is not very sensitive to the SSE date estimations in our joint inversion of the parameters. We use the FastICA algorithm (Hyvarinen \& Oja, 1997) to determine the independent sources and the corresponding mixing matrices. Note that contrary to PCA, the output components of this algorithm are not ordered and are given in random order. As this algorithm does no support data gap in the times series, we perform a spatial averaging of the data with a mean sliding window on $5 \times 5$ pixels, in order to fill the small data gaps in our images and to keep more pixels in our data matrix. Determining the appropriate number of independent components to be considered is one of the main challenges of the ICA method (e.g., Cohen-Waeber et al., 2018; Ebmeier, 2016; Milliner et al., 2018). Selecting too few components may mix different sources together, and selecting too many will result in the splitting of the sources of interest over many components with large errors making their identifications more difficult.

To determine the appropriate number of components, we propose two approaches. First, we use the eigenspectrum derived from a PCA, as previously proposed by Chaussard et al. (2017), and select the number of components that explain at least $80 \%$ of data variance (Figure 4). This procedure allows the number of independent components, $n$, for each track to be selected consistently, based on the data complexity estimated by a PCA. For the Track D041, we select six components, whereas five components are sufficient for the Track A078 to account for the same data variance (Figure 4). In the second approach, we take advantage of the GPS stations present in the area to get some knowledge on the temporal evolution of the signals contained in our InSAR data (displacement and tropospheric). As previously explained, the GPS-TD $L_{O S}$ extracted from GPS 

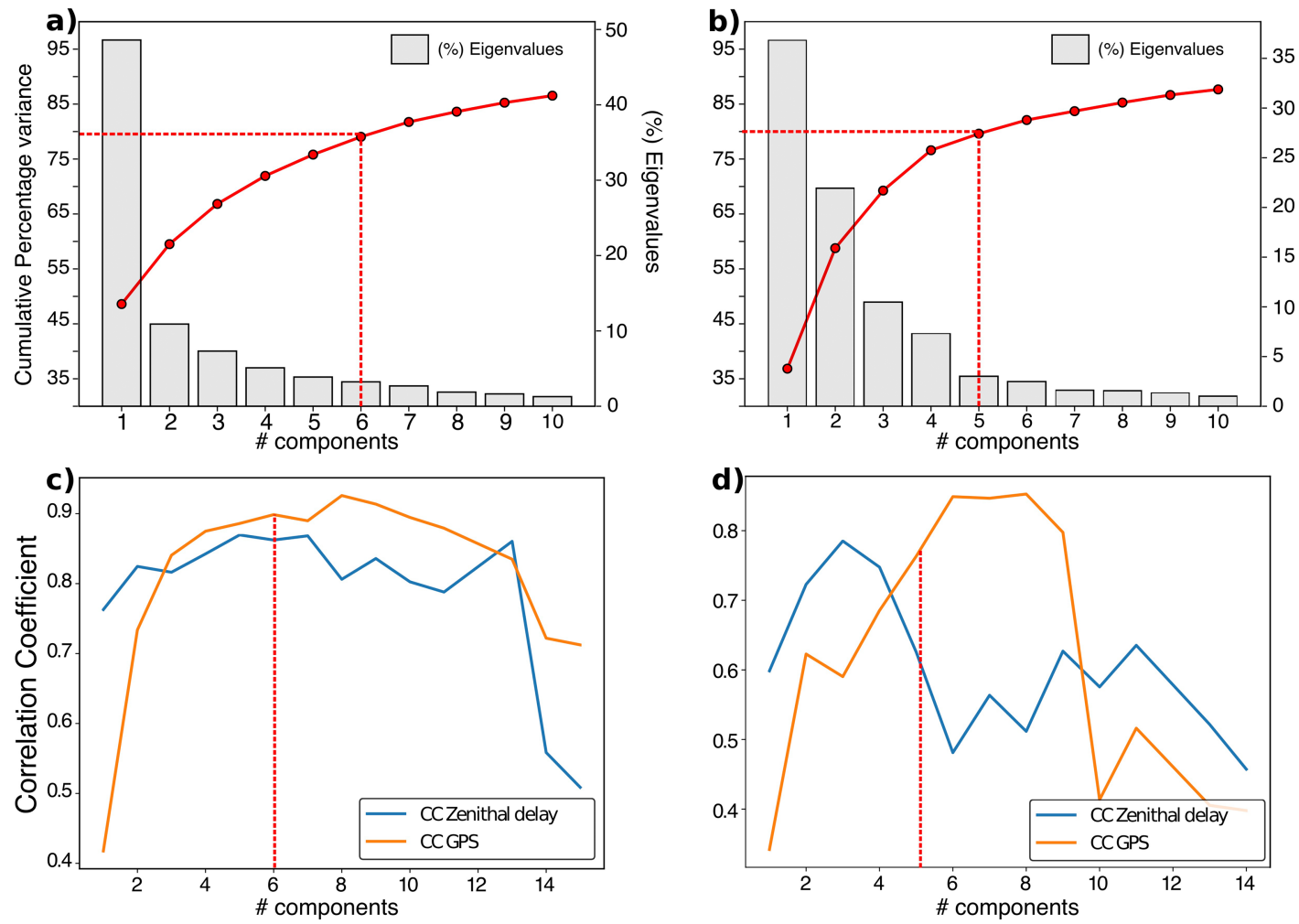

Figure 4. Statistical criteria used to choose the number of components for ICA for both INSAR tracks. (a and c) Track D041. (b and d) Track A078. (top) Percentage of the signal variance explained as a function of the component number with a temporal PCA. Gray histograms are the variance explained by each component, and the red curves are the cumulative variance explained. (bottom) Maximum correlation coefficient for the SSE and the GPS-TD $L_{O S}$ components extracted from the GPS data and their corresponding independent components as a function of the number of components chosen. Vertical red lines indicate the number of components chosen.

(via a PCA, see Figure 2c) gives a good first-order estimate of the tropospheric-related InSAR phase variation with time. We perform an ICA on the detrended GPS data (present in the footprint, 8 stations in descending and 10 in ascending) projected into the radar LOS to extract two independent components, one represents the main features of the tectonic signal in the GPS time series (SSE-ICA), while the second one is a noisy component. We then compare the GPS-TD $L_{O S}$ and SSE-ICA temporal signals with the temporal evolution of the independent components from ICA of the InSAR data time series. To do so, for each imposed number of components in the decomposition, we calculate their correlation coefficient (CC) with GPS-TD $L_{O S}$ and with SSE-ICA. We keep the maximum of these correlation coefficients for GPS-TD $L_{O S}$ and SSE-ICA and plot them as a function of the total number of components used in the decomposition (Figures $4 \mathrm{c}$ and $4 \mathrm{~d}$ ). Doing so, we can check the proximity of the extracted InSAR signals to the independent GPS measurements, in order to identify more objectively the InSAR IC that can be representative of the SSE displacement and the one that can be representative of the tropospheric effects. This also allows us to select quantitatively the optimal number of components: We choose the optimal number of components as the one for which the sum of the two $\mathrm{CC}\left(C C_{Z T D}\right.$ and $\left.C C_{S S E}\right)$ is maximum. The second approach gives results consistent with the first one based on PCA, which reinforces confidence in our final choice of the number of components.

For the descending track, we observe an increase of $C C_{S S E}$ with the number of components between one and four, then a plateau between four and eight components, and a decrease for a larger number of components. The $C C_{Z T D}$ is almost constant (with small variations) up to 12 components and strongly decrease afterward. Our interpretation is that for too few components (less than 4), the SSE signal cannot be separated from the noise, the atmospheric signal, however, has a large amplitude and always appears on a single component. When the number of components is really large (more than 12), the atmospheric signal is then separated in more than one component and becomes more difficult to identify. The sum of both CC is maximal at six components, so we take that value as our optimum number of components. For the ascending track, $C C_{Z T D}$ 


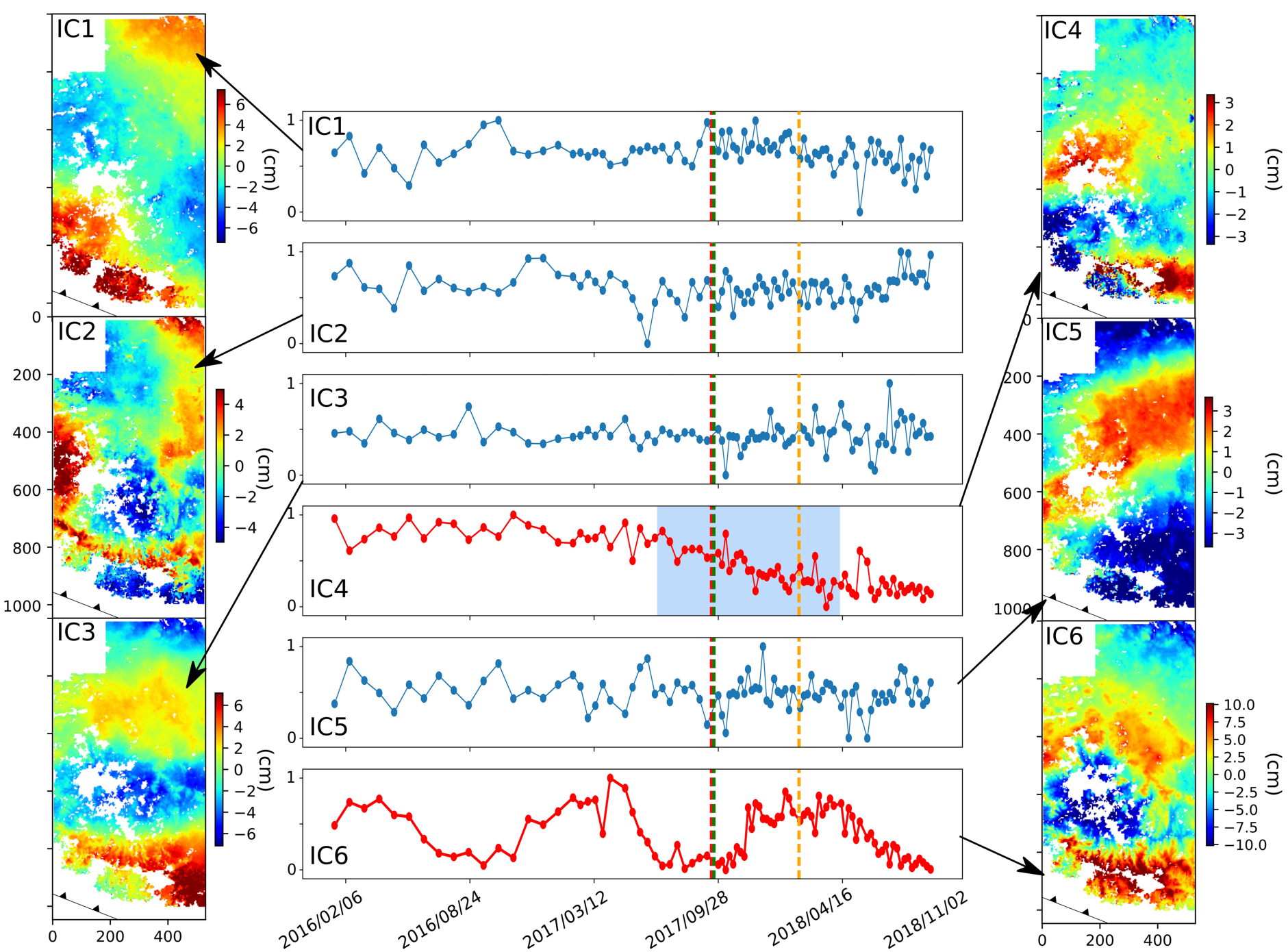

Figure 5. Independent components analysis of InSAR data on descending Track D041 without prior global weather model correction. Middle plot: temporal eigenvectors for the six independent components. The vertical lines show the timing of three major earthquakes that occurred since September 2017. Left and right: maps representing a spatial pattern for each independent component. The IC4 component is consistent with a SSE signal (both phases of the SSE period known from GPS measurements is highlighted in blue). The IC6 component is very consistent with tropospheric temporal variations showing clear seasonal changes. IC1, IC2, IC3, and IC5 are certainly mainly related to the turbulent troposphere, ionosphere or residual orbital error signals, but it is difficult to interpret them individually. All maps are displayed in radar coordinates with an E-W flip to help comparison with other maps.

is larger than 0.6 for three to five components and decreases afterward. $C C_{S S E}$ is maximal for six to eight components (around 0.85 ). The sum of both $\mathrm{CC}$ is maximal for four components; however, this value is very close to the one for five components (1.42 and 1.38). As these values are very close, and because the PCA estimation gives five components, we decide to choose five components as the best compromise.

\subsubsection{Results}

The results of the ICA applied on InSAR time series without previous atmospheric correction from the global weather model are presented in Figures 5 and 6 for descending and ascending tracks, respectively. Results for data previously corrected from GACOS model are presented in Figure S9. Note that the IC numbers in those results are random and their order has no particular meaning. To identify the signals of interest among the ICs, we analyze their temporal evolution using the previously computed $C C_{L T D}$ and $C C_{S S E}$, and we also analyze their spatial distribution. For D041, the IC6 (Figure 5) presents a temporal evolution with seasonal oscillations that are very similar to the GPS-TD $L_{O S}$ vector shown in Figure $2\left(C C_{Z T D}=0.86\right)$, and its amplitude is highly correlated with the topography, as expected for the seasonal variations of the stratified troposphere. We thus interpret IC6 as representing the main contribution of the troposphere. IC4 has a temporal evolution that shows a clear decrease between May 2017 and April 2018, and flatter trend 


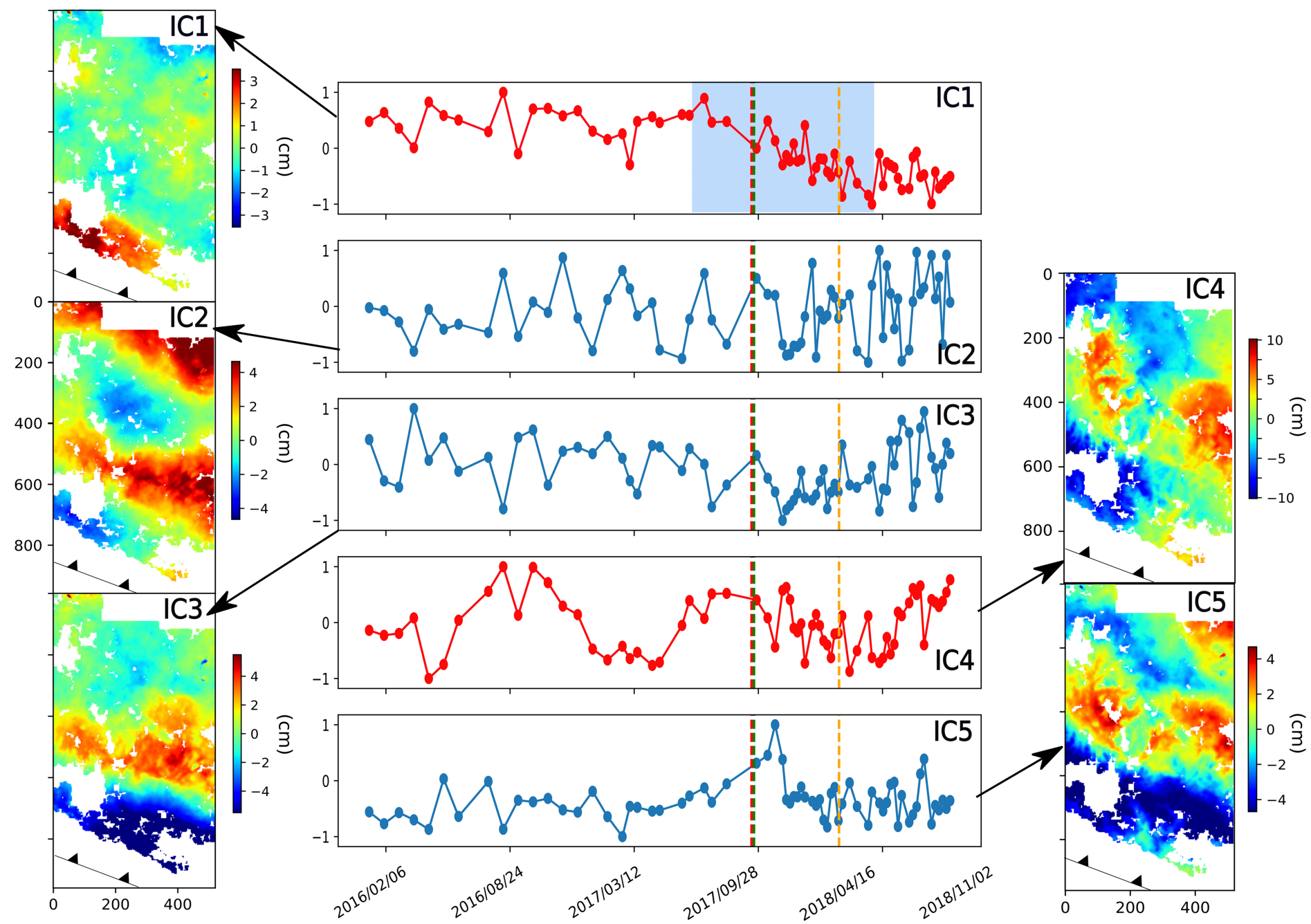

Figure 6. Independent components analysis of InSAR data on ascending Track A078. Same legend as in Figure 5, but here, the SSE pops up in the first component (IC1), and the tropospheric signal in the fourth component (IC4). Maps are in radar geometry with a north-south flip to help comparison with other maps.

segments before and after those dates, as expected for the large SSE transient deformations in the Guerrero area. $C C_{S S E}$ is 0.9 for this component, which indicates a good agreement with the surface displacement signal measured by the GPSs. The spatial pattern is opposite to the inter-SSE signal (Figure S6a) and is similar to its spatial distribution of previous SSE in this region (Bekaert et al., 2015; Cavalié et al., 2013). This component is thus interpreted as the main surface deformation signal from the SSE. The spatial distributions of the amplitude of the first, third, and fifth components (IC1, IC3, and IC5) show long-wavelength signals, and their associated temporal evolutions appear to be varying randomly. Those three components could be related to long-wavelength signals of the turbulent troposphere, ionospheric effects, or residual orbital errors. The second component (IC2) has a spatial distribution showing some correlation with the topography but not everywhere and has a random temporal evolution. This component is more difficult to interpret. However, its amplitude is really small compared to IC6 and explains only $12 \%$ of the signal.

The decomposition of the data previously corrected from the GACOS model (Figure S9) has also a component (IC6) with a temporal evolution similar to the GPS-TD $L_{O S}$ vector $\left(C C_{Z T D}=0.83\right)$ and a spatial pattern correlated with the topography. However, the amplitudes are smaller than when the data are not previously corrected from GACOS. Thus, the GACOS atmospheric model has only partially corrected the seasonal atmospheric contribution. IC5 (Figure S9) has a spatial pattern close to the one obtained without GACOS correction, except in the northern part of the image where there are larger values. It has a temporal evolution similar to the SSE, but with a lower correlation coefficient with the ICA-GPS compared to the case 

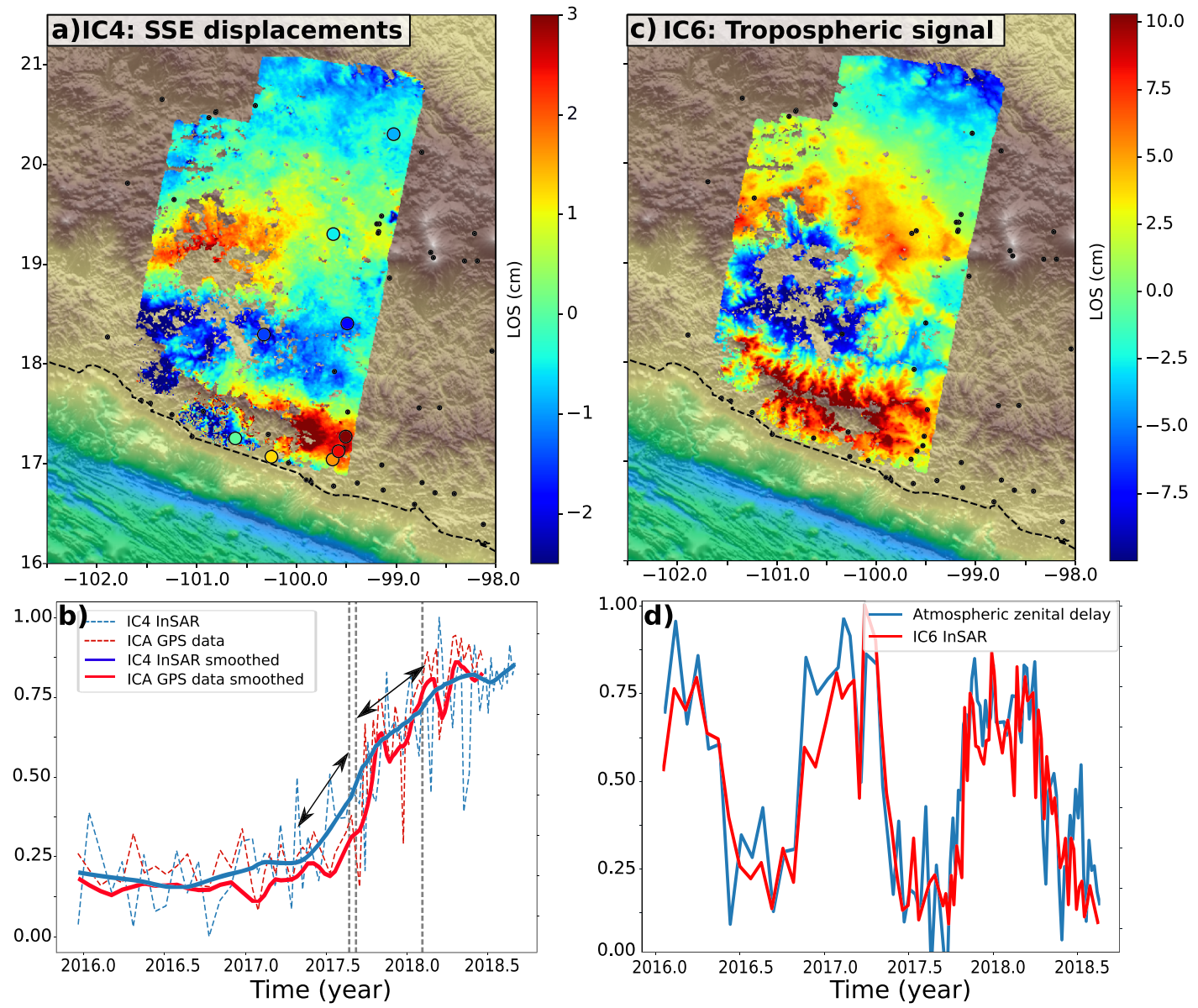

Figure 7. Comparison of ICA components from InSAR (descending Track D041) with respect to ICA components extracted from GPS displacement time series and from GPS-TD $L_{O S}$ time series. (a) Map of amplitude of the SSE (IC4) in centimeters, from InSAR ICA, identified as extracting the SSE surface displacement. Black points show the location of GPS stations. The colored circles represent the SSE displacement extracted from the GPS stations. (b) Temporal evolution. Dashed blue line: SSE-IC4 temporal evolution; dashed red line, ICA-GPS temporal evolution (SSE temporal evolution extracted with ICA from GPS data); solid lines, temporal evolutions smoothed with a mean sliding window. The vertical lines show the timing of the three major earthquakes. The black arrows highlight a change in the slope of the time series that could be associated with earthquakes occurrence. (c) Amplitude map of the tropospheric signal extracted with ICA in centimeters. (d) Red line: tropospheric-ICA vector (IC6) from InSAR; blue line: the GPS-TDL ${ }_{O S}$ from the GPS stations located in the image footprint.

without GACOS correction $\left(C C_{S S E}=0.78\right.$, against 0.9$)$. In the following, we thus decide to consider the case in which the data are not previously corrected from the global weather model.

The ICA for the ascending track A078 (Figure 6) also isolates a component, IC1, with the same temporal and spatial evolution as the expected SSE (with $C C_{S S E}=0.76$ ). IC2 and IC3 show spatially long-wavelength pattern (not correlated to the topography) associated with temporal random evolution. IC4 appears spatially correlated to the topography, and temporally correlated to the GPS-TD $L_{O S}$ vector $\left(C C_{Z T D}=0.625\right)$. IC5 also displays spatial correlation to the topography but temporally the evolution looks noisy, dominated by a few dates.

These results give good confidence that it is possible to isolate the SSE signal and the main atmospheric contribution from the InSAR time series. To get more confidence in our interpretation of the IC, we compare the IC interpreted as the main SSE and tropospheric signals with respect to GPS derived measurements. The IC corresponding to the tropospheric signal is compared with temporal evolution of the GPS-TD $L_{O S}$ (Figures $7 \mathrm{~d}$ and $8 \mathrm{~b}$ ), showing a good correlation $\left(C C_{Z T D}=0.83\right.$ for descending track and $C C_{Z T D}=0.625$ for ascending track). The SSE temporal evolution is shown in Figures $7 \mathrm{~b}$ and $8 \mathrm{~b}$. To facilitate the comparison between the IC obtained by InSAR and GPS, we smooth the vectors with a mean sliding window over five InSAR acquisition dates. After smoothing, we observe a change in the slope of the SSE signal, which occurs at the end of September 2017, with a deceleration (velocity 1.5 and 1.8 times smaller for D071 and A048 

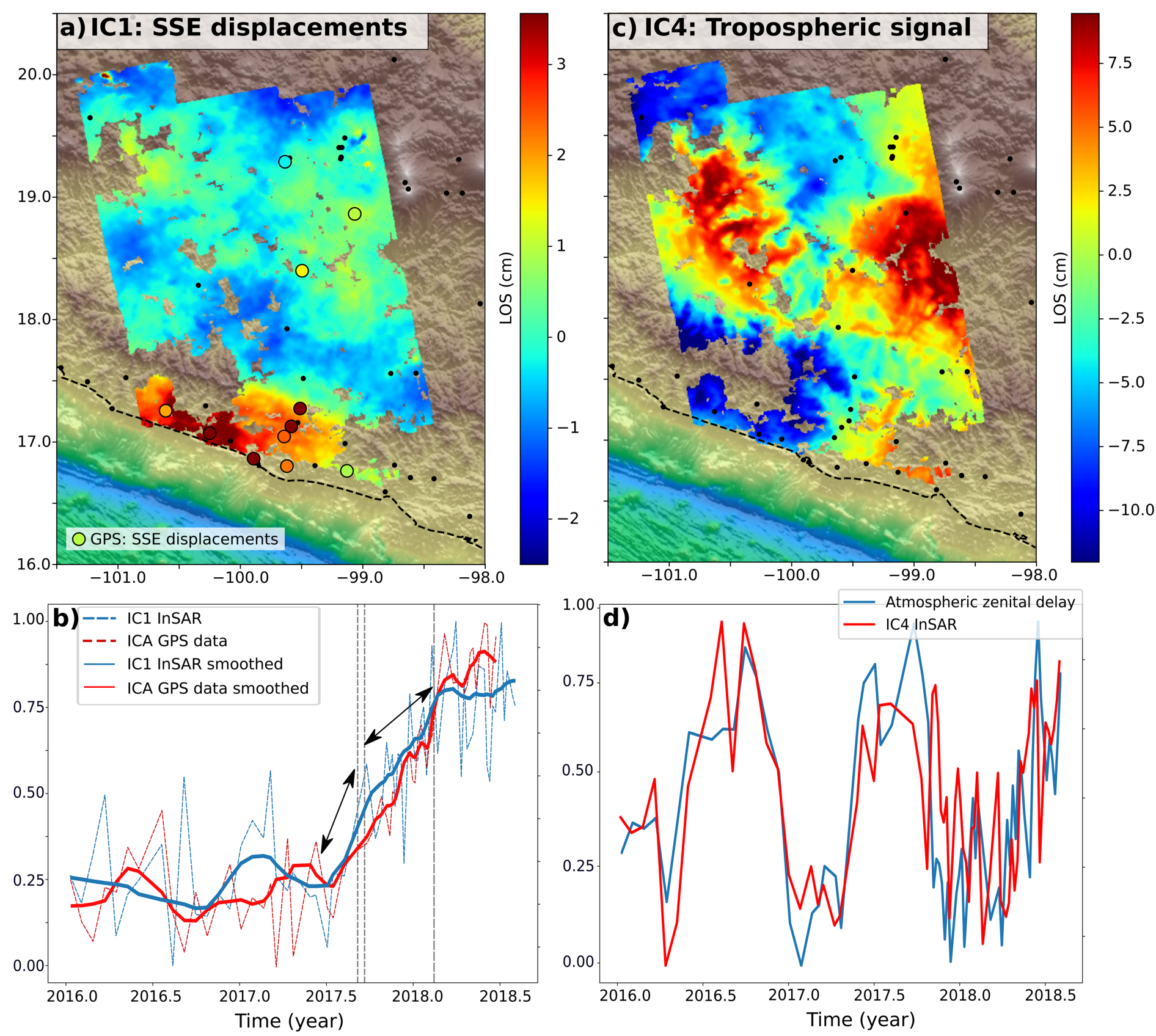

Figure 8. Comparison of ICA components from InSAR (ascending track A078) with respect to ICA components extracted from GPS displacement time series and from GPS-TD $L_{O S}$ time series. Legend as in Figure 7.

respectively). This change of slope occurs just after the September seismic sequence. For both tracks, we were not able to identify in the ICA components that could be clearly related to a possible SSE migration, the latter being likely too small or mixed in several components making its interpretation more difficult.

\section{Comparison and Modeling}

5.1. Comparison: Parametric Decomposition Versus ICA

Our results show that the two approaches (parametric decomposition and ICA), can isolate a signal which is in agreement with the GPS observations of the 2017-2018 SSE in Guerrero. For both methods, the extracted measurement can be related to slip on the subduction interface, a horizontal displacement toward SSW combined with an uplift around the Sierra Madre del Sur (SMdS, Figure 1a) and a subsidence north of it. In both parametric and ICA results the uplift and subsidence surface displacements are well seen in descending 
track, which is mainly sensitive to the vertical displacement, as the horizontal ground deformation is almost orthogonal to the radar LOS (Figures $3 \mathrm{a}$ and 7). The maximum is $4 \mathrm{~cm}$ for the parametric method and $3 \mathrm{~cm}$ for the ICA results, in descending track. In ascending track, both approaches are spatially consistent (Figures 3a and 8). As in descending, the maximum is $4 \mathrm{~cm}$ for the parametric method and $3.5 \mathrm{~cm}$ for the ICA results. In this case, north of the SMdS, the horizontal displacement causes displacements toward the satellite that is partially compensating the subsidence signal going away from the satellite. There are nevertheless some differences between the results of both methods. For the descending track, in the western part of the track, along the coast, we observe, with the ICA decomposition, a gradient of LOS displacement in agreement with motion away from the satellite $(\sim-2.5 \mathrm{~cm}$; Figure 7$)$ that is less considerable than in the parametric decomposition (Figure 3a). On the other hand, the parametric decomposition shows in northern most part of the track (latitude $>20.5^{\circ} \mathrm{N}$ ), a larger signal $(\sim 2 \mathrm{~cm}$ away from satellite), which could be associated with a wrong estimation of the tropospheric temporal pattern by GPS-TD $L_{O S}$ affecting the SSE term estimations. Indeed, this area close to the Gulf of Mexico coast may have different tropospheric temporal pattern than south of it, which could not be well sampled because of the lack of GPS stations here included in the GPS-TD $L_{O S}$ estimation. For the ascending track and for the first phase of the SSE (Figure S7a), we observe in the eastern part of the track a subsidence/uplift bowl pattern close to the epicenter of the Puebla earthquake, which corresponds to the surface displacement of this event. This signal cannot be attributed to the SSE but may be the result of the Puebla earthquake (19 September 17, Mw 7.1). However, the parametric approach cannot separate the SSE from the coseismic signal by adding a Heaviside function (step function) in the parametric decomposition without inducing a trade-off between the functions. This may arise from a lack of data during the initial stage of the SSE and before the earthquake.

Another observation is seen across the Tierra Caliente basin region (see location in Figure 1) from $19.5^{\circ} \mathrm{N}$ to $18.5^{\circ} \mathrm{S}$ of latitude. There, the northern part of the basin is moving toward the satellite with respect to the southern part of the basin (Figures 7a and 8a). As the measurements are similar in ascending and descending tracks (but with a lower amplitude in the ascending results), it could be interpreted as a relative uplift. The signal is not well correlated to the topography and is difficult to explain by SSE slip. It may be related to a residual atmospheric signal in that region at the time of the SSE. If the temporal evolution of the atmospheric signal during the SSE is different in that region compared to the rest of the studied area and shows some residual seasonality, there could be a trade-off between the SSE and the atmospheric signal in the decomposition. Alternatively, it may be caused by hydrological or unknown tectonic signal but so far the geophysical interpretation of this pattern remains unclear.

We reconstruct the SSE signal for each method, and we then compare the amplitude for a pixel window (of $5 \times 5$ ) fixed at the location of the CAYA GPS station (close to the coast, Figure 1a), which is one of the stations mostly affected by the SSE. To reconstruct the signal, for the parametric method, we multiply the SSE time vectors (for the two phases) by the amplitudes ( $\mathrm{C} 1$ and $\mathrm{C} 2$ ) of the pixel at CAYA station coordinates. For the ICA decomposition, we multiply the temporal evolution of the IC corresponding to the SSE by the value of the amplitude map at CAYA location. At this point, the amplitude of the parametric decomposition is $3.9 \mathrm{~cm}$ in descending, and $3.1 \mathrm{~cm}$ in ascending track. The amplitude of the ICA method is $3.5 \mathrm{~cm}$ in descending and $2.9 \mathrm{~cm}$ in ascending. We compare these two reconstructions with the displacements observed at the CAYA GPS station, detrended and converted in LOS (Figure 9).

For the descending track, both methods are in agreement with the GPS data revealing a slope change in the SSE displacement curves around the date of the September earthquakes. The dates are similar in both methods, but both methods overestimate the amplitude of the first phase of the SSE compared to the GPS data (Figure 9). However, ICA amplitudes are close to the GPS data considering the complete time series. For the ascending track, the parametric decomposition is not in agreement with the GPS time series for the first phase of the SSE. In this case, the shape of the basis function does not seem appropriate. The second phase of the SSE looks more coherent with the GPS data. The cumulative amplitude is coherent with the GPS data for this station location.

Despite some minor discrepancies, our results show that both approaches are overall coherent in terms of SSE amplitudes and spatial distribution, which gives us confidence in the robustness of the extracted signal. The temporal evolution is more difficult to analyze concerning the parametric decomposition since it is constrained by the initial parameterization, which could be biased. Indeed, ICA has the advantage of not 

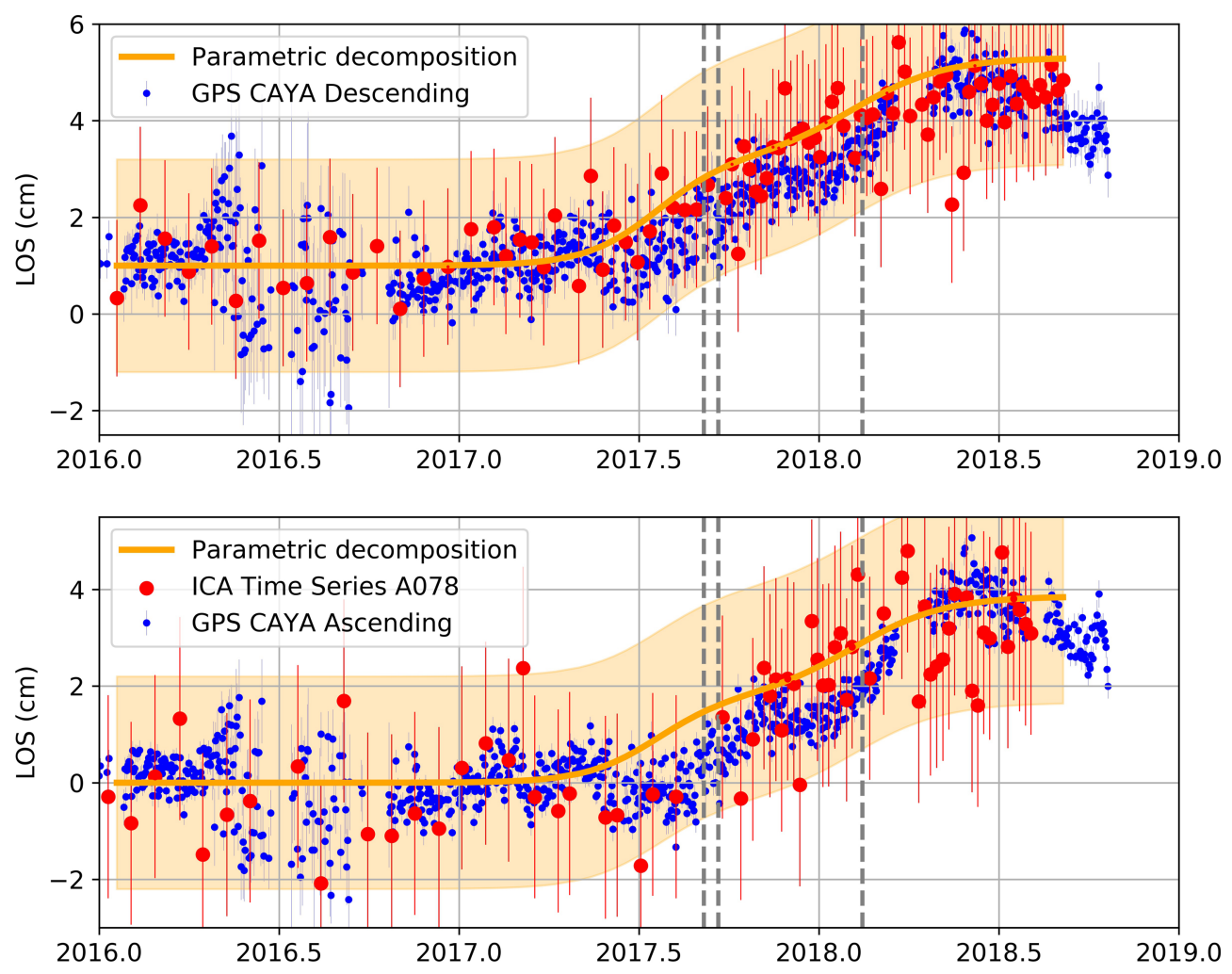

Figure 9. Comparison of the surface LOS displacement of the 2017-2018 SSE, at the location of the CAYA GPS station, estimated from three different approaches. (top) For descending Track D041. (bottom) For ascending Track A078. Blue dots: CAYA GPS time series reprojected along LOS; orange line: parametric reconstruction of the SSE; red dots: displacement reconstructed from the SSE extracted with the ICA method applied to InSAR data (IC4 for descending, and IC1 for ascending) identified as extracted component of the ICA method, applied to InSAR data, identified as representing the SSE surface displacement (IC4 for descending, and IC1 for ascending, see Figures 5 and 6). Some increase of the scatter in GPS data (around 2,016.5) occurred by the sudden change of transmitted data from raw to the Trimble RTX.

requiring a priori information about the form of the transient signal. However, because ICA needs a detrending of the time series prior to the decomposition, we used in our ICA decomposition the data previously detrended from the inter-SSE trend using the parametric approach. This detrending step, which in this case requires an assumption on the SSE dates (because it was done for the inter-SSE period), could also be performed by computing the velocities over the entire time series (detrending from the long-term trend instead of the inter-SSE trend). We tested this approach and observe that it does not change our results significantly. We prefer here to detrend the data from the inter-SSE velocity to be consistent with the parametric approach and with previous studies and models in the regions (Cavalié et al., 2013; Radiguet et al., 2012). Concerning the requirement of having GPS stations in the studied area, with a purely parametric approach, having GPS time series in the region is useful to have an initial guess on the transient time and duration. Regarding the correction from atmospheric delays, ZTD from the GPS data are also used to extract seasonal variations of the atmospheric delays. However, as shown in Figure 2, a temporal evolution extraction with a PCA on the GACOS or ERA-I atmospheric model gives very similar temporal evolutions. With the ICA approach, the GPS data (ZTD and displacements) are used to help choosing the number of components and identifying them. Afterward, only to validate the results of the decomposition in the area where the density of the GPS network is not sufficient to observe with an efficient spatial resolution, the results of the ICA decomposition can be validated with few stations.

\subsection{Modeling}

In order to make an additional confirmation that the LOS displacement extracted by ICA and parametric approach can be attributed to the SSE, we invert the SSE amplitudes extracted with both methods to estimate the slip distribution of this event on the subduction interface and compare then the estimated slip distribution with previous SSE. 


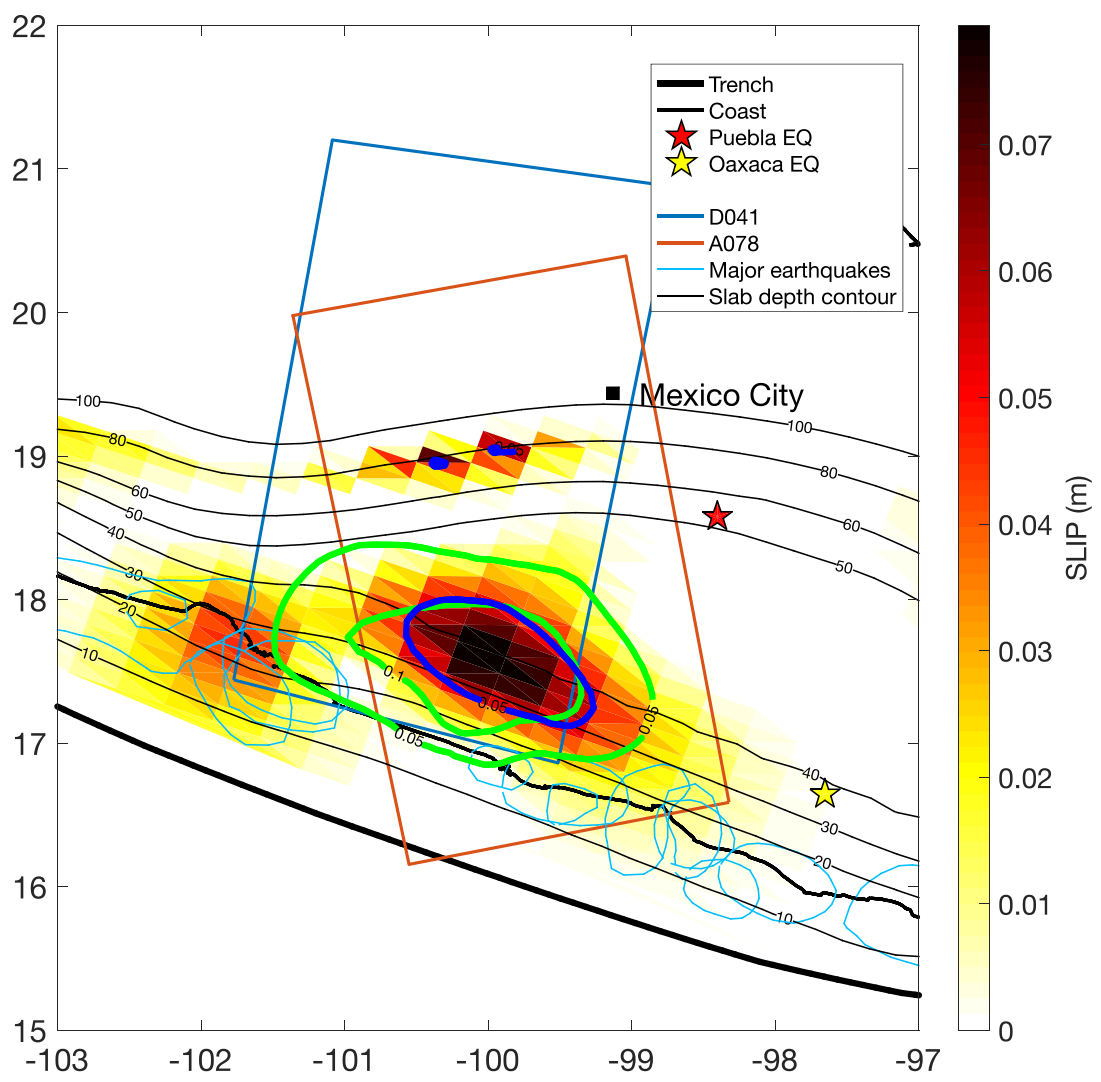

Figure 10. Cumulative slip distribution on the subduction interface for the 2017-2018 SSE inverted from the ICA results. This slip distribution has an equivalent magnitude $\mathrm{Mw}=7.2$. The green contours represent 5 and $10 \mathrm{~cm}$ isocontours of the mean slip distribution of the three past SSEs (2006, 2010, and 2014) (Radiguet et al., 2012, 2016). The thin cyan contours show approximate rupture areas of the major historical earthquakes that occurred on the subduction interface. Stars represent epicenters of the Puebla (MW 7.1, 19 September 2017, in red), and Pinotepa (Mw 7.2, 16 February 2018 in yellow) earthquakes. The orange and dark blue rectangles represent the footprints of the two InSAR tracks. The thin black lines are the isodepth of the plate interface every $10 \mathrm{~km}$, the medium black line the coast, and the bold black line the Middle America Trench.

The SSE surface displacements consist of the two amplitude maps extracted by ICA (IC4 for ascending and IC1 for descending). We perform a static inversion in an elastic medium, using a linear least squares algorithm (Tarantola, 2005) with the regularization scheme of Radiguet et al. (2011). The 3-D slab geometry is similar to Radiguet et al. (2016) and takes into account the flat-slab segment of the plate interface (Pérez-Campos et al., 2008), with a ramp between the trench and $150 \mathrm{~km}$ north of the trench, then the slab is flat at $40 \mathrm{~km}$ depth. Our forward model (Green's functions) assumes an elastic half-space and is computed using the Okada (1992) dislocation model. For numerical reasons, we reduce the number of pixels for the inversion. We resample the amplitude map from $5.10^{5}$ to 2,770 pixels for the descending track and 2,234 pixels for the ascending one. Because our SSE signal is long-wavelength, we choose a uniform downsampling rather than quadtree algorithms (Jónsson et al., 2002). To associate an uncertainty at each InSAR sampled data sets, we average the residual map of the parametric method in each subsampled zone (Figures S3b and S3d). This measure gives an estimate of the dispersion of our data through the complete time series. These errors provide relative weight between pixels, and allows us to weight each track relatively. Note that we neglect covariance between pixels in our inversion. This gives more weight to the data, and thus tends to produce higher $\chi_{2}$ (Text S1) and rougher solutions with respect to solutions accounting for covariance.

We test the variability of our model to the smoothing parameters through $\mathrm{L}$ curves: We perform an exploration of the damping value $\left(\sigma_{m 0}\right)$, and then we choose the best compromise between the $\chi_{2}$ (Text S1) and small $L_{2}$ norm of the solution (Figure S10). We impose to the model a non-negativity constraint, as well as a fixed rake perpendicular to the trench. The data misfit of the selected model is $\chi_{2}=0.23$. We also implement 

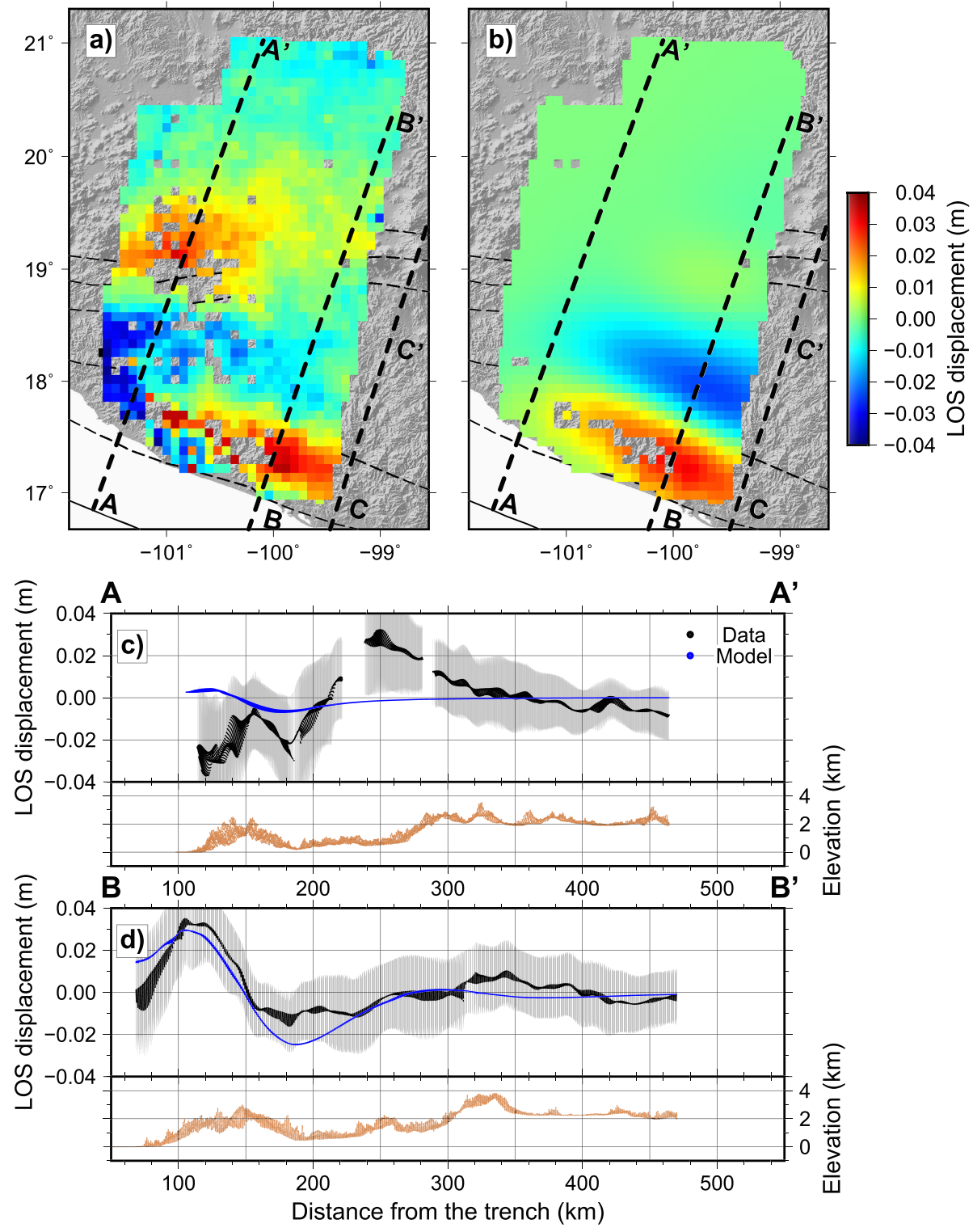

Figure 11. Comparison between observed and inverted surface SSE displacements. (a) The data used for the inversion. (b) Modeled surface displacement. (c) Profile A along the D041 track (width of $5 \mathrm{~km}$ ). The black dots are the data, the blue dots display the model, and brown dots the topographic profile in this area. (d) Profile B along the D041 track. The annotations are the same as in (c).

a model using the results of the parametric method as input data with the same model parameters than with ICA data and obtain a data misfit of $\chi_{2}=0.85$.

Our inversion results, for both inverted data sets, show a slip pattern along the subduction interface similar to previous SSE models (Figures 10 and S11) (Bekaert et al., 2015; Cavalié et al., 2013; Radiguet et al., 2012). The main SSE slip patch is located in the coastal area, between 20 and $40 \mathrm{~km}$ depth, on the deep part of the ramp located above the flat segment of the slab, and extend $250 \mathrm{~km}$ along strike.

The equivalent moment magnitude calculated for the 2017-2018 SSE event, using ICA data set, is Mw = 7.2 and slightly lower than the magnitudes of past events (past events have magnitudes between 7.3 and 7.5). This is expected as the surface displacements observed for this event are lower than previous ones. For comparison, the model obtained using the results of the parametric decomposition is shown in Figure S11. The main slip patch is quite similar to a slightly larger magnitude (equivalent Mw 7.4) in this case. 

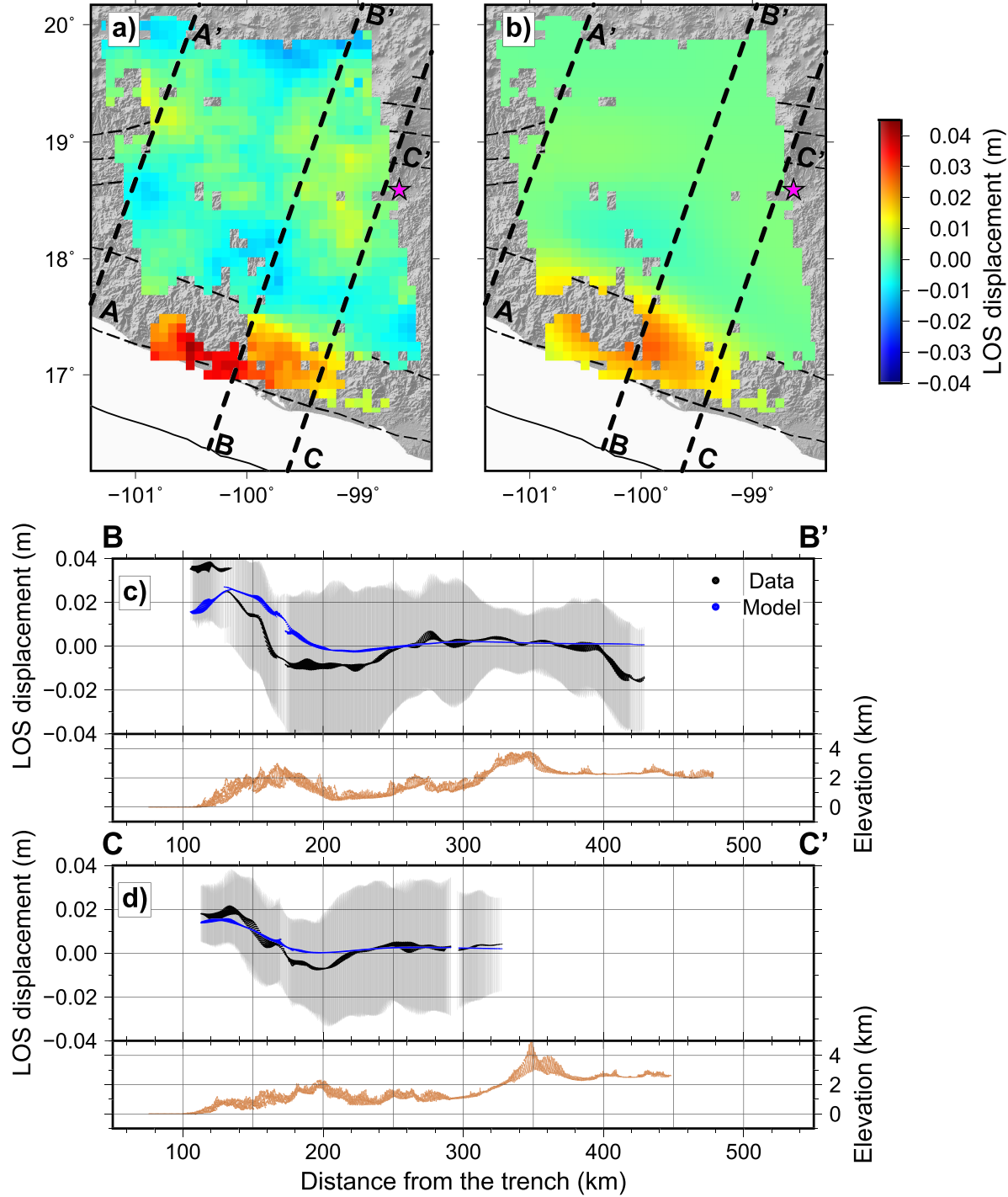

Figure 12. Comparison between observed and modeled SSE displacements for inversions. (a) The data used for the inversion for Track A078. (b) Surface displacement predicted by the model. (c) Profile B perpendicular to the trench with the data as black dots with uncertainties in gray, and the model in blue dots (width of $5 \mathrm{~km}$ ). The brown dots represent the topography in meters. (d) Profile C along the A078 track with in black dots are the data, in blue dots the model and down the associated topographic profile.

Overall, the model (with both methods) explains well the data, with the same pattern of displacement toward the satellite at the coast and away from the satellite further north. However, the deformation signal in the south of the Tierra Caliente area (see section 5.1) cannot be explained by our model (Figures 11 and 12). As discussed in section 5.1, it is not clear if this signal is a real displacement or due to residual tropospheric signal leaking into the SSE component. In any case, it cannot be modeled by slip on the interface and consequently may be responsible for an artificial deep slip in the northern part of the slip model. We analyze three profiles along the track ( $\mathrm{a}-\mathrm{c}$ in Figures 11 and 12). Profile $\mathrm{B}$ is common to both tracks. As previously explained, Profile A shows that the model does not reproduce the Tierra Caliente signal. We observe that the model using ICA results underestimates $(\sim 15 \%)$ the amplitude of the uplift (at the coast) for the descending track (Figure 11) but overestimates $(\sim 45 \%)$ the amplitudes in the ascending track (Figure 12). Those variations are also observed in the inversion using parametric results, suggesting that some residual atmospheric signal probably related to the topography of the Sierra Madre del Sur may have leaked into the SSE signal in that region. Nonetheless, the first-order deformation signal extracted with the ICA decomposition is 
compatible with the slip on the subduction interface along the convergence direction and with a slip distribution similar to previous SSEs.

\section{Conclusion}

The temporal densification of the InSAR data with Sentinel-1 makes it possible to generate interferograms of good quality, which can be unwrapped over large regions and results in improved spatial coverage of InSAR measurements. However, separating tectonic deformation from the atmospheric signal remains a challenge, especially in large mountainous areas, as in the Guerrero state of Mexico. In such regions, the atmospheric signal can be larger than the transient deformation and can have complex temporal behavior. It is therefore difficult to extract SSEs deformation signals, like those caused by SSE in subduction zones. Despite these difficulties, we show here that using appropriate InSAR source separation techniques, we can extract from InSAR, at regional-scale, slow aseismic transient signal. To achieve this, we first explore the benefits of correcting the InSAR time series using predictive estimations from global weather models (ERA-I and HRES ECMWF models). We conclude that, for the two methods investigated in our study (parametric and ICA), initial corrections on time series from global weather models does not improve the separation of atmospheric from tectonic signals, mainly because amplitudes of atmospheric delays are not accurately predicted by these models. However, we show that the temporal evolution of atmospheric delays captured by the GPS-TD $L_{O S}$ data, or extracted from global weather models are very similar and can be used as an input to the parametric decomposition to correct the InSAR time series.

The second objective of this study was to compare the benefits and limitations of two methods of signal decompositions (parametric and ICA) to extract the SSE signal in the Guerrero area, Mexico. For the parametric decomposition, the principal limitation is the requirement of some a priori knowledge about the searched signal (SSE time and duration and atmospheric component), which strongly controls the results. However, it has the advantage to be simple, linear, and to provide uncertainties associated with the estimated parameters. Alternatively, the ICA, being a blind approach, does not require any a priori of the signal parameters. Its limitations are the necessity to assess the adequate number of independent components and the subsequent interpretation of these components. We show in this paper that the ICA approach can be powerful to extract the SSE spatial pattern and its temporal evolution. We propose an original approach to validate the component identification by comparison with external GPS data. We also show the possibility with the ICA to extract complex atmospheric delays without a priori information on the evolution of this signal, which can be validated with the GPS-TD $L_{O S}$. Despite some limitations due to possible trade-off between parameters in the parametric approach or due to the need to detrend the time series for ICA, both methods are complementary and several possibilities can be envisioned depending on the study area. ICA alone appears as a reasonable choice in the case when there is no a priori knowledge on the deformation and no other data are available. In large tectonically active areas like subduction zone, it is likely to have some a priori about expected deformation and also to have data from a few permanent GPS stations. In this case, a hybrid approach can be conducted combining ICA with a parametric model as done in this study. If no GPS-ZTD data are available or if they are not representative of the seasonal atmospheric variations of the studied area, the ZTD time series can be replaced by the temporal evolution of global weather models despite their poor spatial resolution. Obviously, a large number of permanent GPS stations well distributed across the study area and in a large altitude range is more beneficial; however, we have shown that using the PCA combining the ZTD time series of a dozen of stations using the ZTD in the parametric approach is enough to capture the first order of the atmospheric signal. In the best configuration, some GPS stations can capture the tectonic signal of interest. Even if it is not required, it will help to design the parametric approach or to choose and identify the number of components in the ICA approach. For both approaches, it can help to validate their result and provide estimations of their uncertainties. Using a hybrid approach has also proved to be interesting when performing inversion to get the slip distribution model. Comparing the model results inverted from surface displacement provided by each method helps in determining the robust features, which should be common in both models.

Our data show some complexity in the temporal evolution of the SSE, with a change of displacement velocity around September 2017. This reflects a possible interaction between the slow slip and the September 2017 seismic sequence, which deserves further investigations. We provide a preliminary model of slip distribution on the subduction interface and observe that the main slip patch occurs between 20 and $40 \mathrm{~km}$ depth at the plate interface. The SSE has an equivalent moment magnitude of Mw 7.2. Its amplitude and spatial 
extension are slightly lower but compatible with the previous events (2006, 2009-2010, and 2014). However, several second-order features extracted in the surface displacement (either in the inter-SSE component or in the SSE component) are not consistent with the expected interseismic and SSE signals and remain to be explained. Some of those could be related to residual atmospheric signal present in the displacement signal. One way to estimate better those ambiguities will be to involve more GPS data, and also to use the adjacent Sentinel-1 tracks that are partially overlapping the ones we have just processed, and also to use other InSAR data like ALOS-2 images.

\section{Acknowledgments}

We thank Jorge Jara, Roland Bürgmann, Sylvain Michel, Adriano Gualandi, and Susanne Ebmeier for fruitful discussions about this work as well as Franck Thollard. Sentinel-1 data are available online (https:// scihub.copernicus.eu), and GPS data were provided by the National Seismological Service of Mexico (SSN) and Department of Seismology, UNAM, whose staff are acknowledged for station maintenance and data acquisition. GPS data, and results are available at https://doi.org/10. 5281/zenodo. 3666788 website. The FastICA software is available from webpages of the Aalto University (research.ics.aalto./ica/software.shtml) and the University of Helsinki, Finland (www.cs.helsinki.fi/u/ ahyvarin/code/isctest/). All the computations presented in this paper were performed using the GRICAD infrastructure (https://gricad. univ-grenoble-alpes.fr), which is partly supported by the EquipMeso project (Reference ANR-10-EQPX-29-01) of the PIA supervised by the French Agence Nationale pour la Recherche. This research was supported by the CNES (L. Maubant PhD funding and Grant APR-CNES for projet SSEMEX), Labex OSUG@2020, and Japan Aerospace Exploration Agency (JAXA) EO-RA2 proposal (ER2A2N021). S. D.'s contribution is supported by the Natural Environment Research Council through the Looking into the Continents from Space (LiCS) large grant (NE/K011006/1) and the Centre for the Observation and modeling of Earthquakes, Volcanoes and Tectonics (COMET). The Editors and the two anonymous reviewers are gratefully acknowledged for their valuable comments.

\section{References}

Bürgmann, R. (2000). Synthetic aperture radar interferometry to measure Earth's surface topography and its deformation. Annual Review of Earth and Planetary Sciences, 28, 169-209. https://doi.org/10.1146/annurev.earth.28.1.169

Bartlow, N. M., Wallace, L. M., Beavan, R. J., Bannister, S., \& Segall, P. (2014). Time-dependent modeling of slow slip events and associated seismicity and tremor at the Hikurangi subduction zone, New Zealand. Journal of Geophysical Research: Solid Earth, 119, 734-753. https://doi.org/10.1002/2013JB010609

Béjar-Pizarro, M., Notti, D., Mateos, R. M., Ezquerro, P., Centolanza, G., Herrera, G., et al. (2017). Mapping vulnerable urban areas affected by slow-moving landslides using Sentinel-1 InSAR data. Remote Sensing, 9(9), 876. https://doi.org/10.3390/rs9090876

Bekaert, D. P. S., Hooper, A., \& Wright, T. J. (2015a). A spatially variable power law tropospheric correction technique for InSAR data. Journal of Geophysical Research: Solid Earth, 120, 1345-1356. https://doi.org/10.1002/2014JB011557.1

Bekaert, D. P. S., Hooper, A., \& Wright, T. J. (2015b). Reassessing the 2006 Guerrero slow-slip event, Mexico. Journal of Geophysical Research: Solid Earth, 120, 1357-1375. https://doi.org/10.1002/2014JB011558

Bekaert, D. P. S., Segall, P., Wright, T. J., \& Hooper, A. J. (2016). A network inversion filter combining GNSS and InSAR for tectonic slip modeling. Journal of Geophysical Research: Solid Earth, 121, 2069-2086. https://doi.org/10.1002/2015JB012638

Bekaert, D. P. S., Walters, R. J., Wright, T. J., Hooper, A. J., \& Parker, D. J. (2015). Statistical comparison of InSAR tropospheric correction techniques. Remote Sensing of Environment, 170(track 255), 40-47. https://doi.org/10.1016/j.rse.2015.08.035

Beroza, G. C., \& Ide, S. (2011). Slow earthquakes and nonvolcanic tremor. Annual Review of Earth and Planetary Sciences, 39(1), 271-296. https://doi.org/10.1146/annurev-earth-040809-152531

Cavalié, O., Doin, M.-p., Lasserre, C., \& Briole, P. (2007). Ground motion measurement in the Lake Mead area, Nevada, by differential synthetic aperture radar interferometry time series analysis: Probing the lithosphere rheological structure. Journal of Geophysical Research, 112, B03403. https://doi.org/10.1029/2006JB004344

Cavalié, O, Lasserre, C., Doin, M. P., Peltzer, G., Sun, J., Xu, X., \& Shen, Z. K. (2008). Measurement of interseismic strain across the Haiyuan fault (Gansu, China), by InSAR. Earth and Planetary Science Letters, 275(3-4), 246-257. https://doi.org/10.1016/j.epsl.2008.07.057

Cavalié, O., Pathier, E., Radiguet, M., Vergnolle, M., Cotte, N., Walpersdorf, A., et al. (2013). Slow slip event in the Mexican subduction zone: Evidence of shallower slip in the Guerrero seismic gap for the 2006 event revealed by the joint inversion of InSAR and GPS data. Earth and Planetary Science Letters, 367, 52-60. https://doi.org/10.1016/j.epsl.2013.02.020

Chaussard, E., Milillo, P., Bürgmann, R., Perissin, D., Fielding, E. J., \& Baker, B. (2017). Remote sensing of ground deformation for monitoring groundwater management practices: Application to the Santa Clara Valley During the 2012-2015 California Drought. Journal of Geophysical Research: Solid Earth, 122, 8566-8582. https://doi.org/10.1002/2017JB014676

Cohen-Waeber, J., Bürgmann, R., Chaussard, E., Giannico, C., \& Ferretti, A. (2018). Spatiotemporal patterns of precipitation-modulated landslide deformation from independent component analysis of InSAR time series. Geophysical Research Letters, 45, 1878-1887. https:// doi.org/10.1002/2017GL075950

Comon, P. (1994). Independent component analysis, A new concept? Signal Processing, 36(3), 287-314. https://doi.org/10.1016/ 0165-1684(94)90029-9

Daout, S., Doin, M.-p., Peltzer, G., Lasserre, C., Socquet, A., Volat, M., \& Sudhaus, H. (2018). Strain partitioning and present-day fault kinematics in NW Tibet from Envisat SAR interferometry. Journal of Geophysical Research: Solid Earth, 123, 2462-2483. https://doi.org/ 10.1002/2017JB015020

Daout, S., Doin, M.-P., Peltzer, G., Socquet, A., \& Lasserre, C. (2017). Large-scale InSAR monitoring of permafrost freeze-thaw cycles on the Tibetan Plateau. Geophysical Research Letters, 44, 901-909. https://doi.org/10.1002/2016GL070781

Daout, S., Sudhaus, H., Kausch, T., Steinberg, A., \& Dini, B. (2019). Interseismic and postseismic shallow creep of the North Qaidam thrust faults detected with a multitemporal InSAR analysis. Journal of Geophysical Research: Solid Earth, 124, 7259-7279. https://doi.org/10. 1029/2019JB017692

DeMets, C., Gordon, R. G., \& Argus, D. F. (2010). Geologically current plate motions. Geophysical Journal International, 181(1), 1-80. https://doi.org/10.1111/j.1365-246X.2009.04491.x

Doin, M.-P., Lasserre, C., Peltzer, G., Cavalié, O, \& Doubre, C. (2009). Corrections of stratified tropospheric delays in SAR interferometry: Validation with global atmospheric models. Journal of Applied Geophysics, 69(1), 35-50. https://doi.org/10.1016/j.jappgeo.2009.03.010

Doin, M.-P., Lodge, F., Guillaso, S., Jolivet, R., Lasserre, C., Ducret, G., et al. (2011). Presentation of the small baseline NSBAS processing chain on a case example: The Etna deformation monitoring from 2003 to 2010 using Envisat data. In Proceedings of the ESA 'Fringe 2011 Workshop', (19-23 September 2011) (pp. 3434-3437). Frascati, Italy.

Doin, M.-P., Twardzik, C., Ducret, G., Lasserre, C., Guillaso, S., \& Jianbao, S. (2015). InSAR measurement of the deformation around Siling Co Lake: Inferences on the lower crust viscosity in central Tibet. Journal of Geophysical Research: Solid Earth, 120, 5290-5310. https:// doi.org/10.1002/2014JB011768

Ebmeier, S. K. (2016). Application of independent component analysis to multitemporal InSAR data with volcanic case studies. Journal of Geophysical Research: Solid Earth, 121, 8970-8986. https://doi.org/10.1002/2016JB013765

Elliott, J. R., Walters, R. J., \& Wright, T. J. (2016). The role of space-based observation in understanding and responding to active tectonics and earthquakes. Nature Communications, 7(1), 13844. https://doi.org/10.1038/ncomms13844

Floyd, M. A., Walters, R. J., Elliott, J. R., Funning, G. J., Svarc, J. L., Murray, J. R., et al. (2016). Spatial variations in fault friction related to lithology from rupture and afterslip of the 2014 South Napa, California, earthquake. Geophysical Research Letters, 43, 6808-6816. https:// doi.org/10.1002/2016GL069428

Frank, W. B., Shapiro, N. M., Husker, A. L., Kostoglodov, V., Bhat, H. S., \& Campillo, M. (2015). Along-fault pore-pressure evolution during a slow-slip event in Guerrero, Mexico. Earth and Planetary Science Letters, 413, 135-143. https://doi.org/10.1016/j.epsl.2014.12.051 
Gomba, G., Rodriguez Gonzalez, F., \& De Zan, F. (2017). Ionospheric phase screen compensation for the Sentinel-1 TOPS and ALOS-2 ScanSAR modes. IEEE Transactions on Geoscience and Remote Sensing, 55(1), 223-235. https://doi.org/10.1109/TGRS.2016.2604461

Grandin, R. (2015). Interferometric processing of SLC Sentinel-1 TOPS data. Fringe 2015, 731, 36. https://doi.org/10.1109/TGRS.2015. 2497902

Grandin, R. (2017). Interferometric processing of SLC Sentinel-1 TOPS data. In FRINGE'15: Advances in the Science and Applications of SAR Interferometry and Sentinel-1 InSAR Workshop, 23-27 March 2015, Mar 2015 Frascati, Italy.

Grandin, R., Doin, M.-p., Bollinger, L., Pinel-puysségur, B., Ducret, G., \& Jolivet, R. (2012). Long-term growth of the Himalaya inferred from interseismic InSAR measurement. Geology, 40, 1059-1062. https://doi.org/10.1130/G33154.1

Gualandi, A., Avouac, J. P., Galetzka, J., Genrich, J. F., Blewitt, G., Adhikari, L. B., et al. (2017). Pre- and post-seismic deformation related to the 2015, Mw7.8 Gorkha earthquake, Nepal. Tectonophysics, 714-715, 90-106. https://doi.org/10.1016/j.tecto.2016.06.014

Gualandi, A., \& Belardinelli, E. S. M. E. (2015). Blind source separation problem in GPS time series. Journal of Geodesy, 90, 323-341. https:// doi.org/10.1007/s00190-015-0875-4

Gualandi, A., Perfettini, H., Radiguet, M., Cotte, N., \& Kostoglodov, V. (2017). GPS deformation related to the Mw7.3, 2014, Papanoa earthquake (Mexico) reveals the aseismic behavior of the Guerrero seismic gap. Geophysical Research Letters, 44, 6039-6047. https://doi. org/10.1002/2017GL072913

Hanssen, R. (2001). Radar interferometry: Data interpretation and error analysis. Dordrecht; Boston: Kluwer Academic.

Hetland, E. A., Musé, P, Simons, M., Lin, Y. N., Agram, P. S., \& Dicaprio, C. J. (2012). Multiscale InSAR Time Series (MInTS) analysis of surface deformation. Journal of Geophysical Research, 117, B02404. https://doi.org/10.1029/2011JB008731

Husker, A., Frank, W. B., Gonzalez, G., Avila, L., Kostoglodov, V., \& Kazachkina, E. (2019). Characteristic tectonic tremor activity observed over multiple slow slip cycles in the Mexican subduction zone. Journal of Geophysical Research: Solid Earth, 124, 599-608. https://doi. org/10.1029/2018JB016517

Hyvarinen, A., Karhunen, J., \& Oja, E. (2004). Independent component analysis. Hoboken: John Wiley. https://doi.org/10.1007/ 978-3-540-92910-913

Hyvarinen, A., \& Oja, E. (1997). A fast fixed-point alogrithm for independent component analysis. Neural Computation, 9, 1483-1492. https://doi.org/10.1162/neco.1997.9.7.1483

Jónsson, S., Zebker, H., Segall, P., \& Amelung, F. (2002). Fault slip distribution of the 1999 Mw 7.1 Hector Mine, California, earthquake, estimated from satellite radar and GPS measurements. Bulletin of the Seismological Society of America, 92(4), 1377-1389. https://doi.org/ $10.1785 / 0120000922$

Jolivet, R., Agram, P. S., Lin, N. Y., Simons, M., Doin, M.-p., Peltzer, G., \& Li, Z. (2014). Journal of Geophysical Research: Solid Earth Improving InSAR geodesy using Global Atmospheric Models. Journal of Geophysical Research: Solid Earth, 119, 2324-2341. https://doi. org/10.1002/2013JB010588.Received

Jolivet, R., Grandin, R., Lasserre, C., Doin, M.-p., \& Peltzer, G. (2011). Systematic InSAR tropospheric phase delay corrections from global meteorological reanalysis data. Geophysical Research Letters, 38, L17311. https://doi.org/10.1029/2011GL048757

Kazachkina, E., Cotte, N., Jara, J., Kostoglodov, V., Radiguet, M., \& Walpersdorf, A. (2018). 2017 SSE in Guerrero interacts with forearc crustal faults, major earthquakes and SSE in Oaxaca, Mexico. American Geophysical Union, Fall Meeting 2018, abstract \#T43E-0436.

Kostoglodov, V., Singh, S. K., Santiago, J. A., Franco, S. I., Larson, K. M., Lowry, A. R., \& Bilham, R. (2003). A large silent earthquake in the Guerrero seismic gap, Mexico. Geophysical Research Letters, 30(15), 1807. https://doi.org/10.1029/2003GL017219

López-Quiroz, P., Doin, M.-p., Tupin, F., Briole, P., \& Nicolas, J. M. (2009). Time series analysis of Mexico City subsidence constrained by radar interferometry. Journal of Applied Geophysics, 69(1), 1-15. https://doi.org/10.1016/j.jappgeo.2009.02.006

Larson, K. M., Kostoglodov, V., Miyazaki, S., \& Santiago, J. A. S. (2007). The 2006 aseismic slow slip event in Guerrero, Mexico: New results from GPS. Geophysical Research Letters, 34, L13309. https://doi.org/10.1029/2007GL029912

Larson, K. M., Lowry, A. R., Kostoglodov, V., Hutton, W., Sánchez, O., Hudnut, K., \& Suárez, G. (2004). Crustal deformation measurements in Guerrero, Mexico. Journal of Geophysical Research, 109, B04409. https://doi.org/10.1029/2003JB002843

Li, Z., Fielding, E. J., Cross, P., \& Muller, J. P. (2006). Interferometric synthetic aperture radar atmospheric correction: GPS topography-dependent turbulence model. Journal of Geophysical Research, 111, B02404. https://doi.org/10.1029/2005JB003711

Li, Z., Muller, J. P., \& Cross, P. (2003). Comparison of precipitable water vapor derived from radiosonde, GPS, and Moderate-Resolution Imaging Spectroradiometer measurements. Journal of Geophysical Research, 108(D20), 4651. https://doi.org/10.1029/2003JD003372

Li, Z., Muller, J. P., Cross, P., \& Fielding, E. J. (2005). Interferometric synthetic aperture radar (InSAR) atmospheric correction: GPS, Moderate Resolution Imaging Spectroradiometer (MODIS), and InSAR integration. Journal of Geophysical Research, 110, B03410. https:// doi.org/10.1029/2004JB003446

Lin, Y. N. N., Simons, M., Hetland, E. A., Muse, P., \& Dicaprio, C. (2010). A multiscale approach to estimating topographically correlated propagation delays in radar interferograms. Geochemistry, Geophysics, Geosystems, 11, Q09002. https://doi.org/10.1029/2010GC003228

Lowry, R., Larson, K. M., Kostoglodov, V., \& Bilham, R. (2001). Transient fault slip in Guerrero, southern Mexico. Geophysical Research Letters, 28(19), 3753-3756

Mackenzie, D., Elliott, J. R., Altunel, E., Walker, R. T., Kurban, Y. C., Schwenninger, J. L., \& Parsons, B. (2016). Seismotectonics and rupture process of the M W 7.1 2011 Van reverse-faulting earthquake, eastern Turkey, and implications for hazard in regions of distributed shortening. Geophysical Journal International, 206(1), 501-524. https://doi.org/10.1093/gji/ggw158

Melgar, D., Pérez-Campos, X., Ramirez-Guzman, L., Spica, Z., Espíndola, V. H., Hammond, W. C., \& Cabral-Cano, E. (2018). Bend faulting at the edge of a flat slab: The 2017 Mw7.1 Puebla-Morelos, Mexico earthquake. Geophysical Research Letters, 45, 2633-2641. https://doi. org/10.1002/2017GL076895

Melgar, D., Ruiz-Angulo, A., Garcia, E. S., Manea, M., Manea, V. C., Xu, X., et al. (2018). Deep embrittlement and complete rupture of the lithosphere during the Mw8.2 Tehuantepec earthquake. Nature Geoscience, 11, 18-25. https://doi.org/10.1038/s41561-018-0229-y

Milliner, C., Materna, K., Bürgmann, R., Fu, Y., Moore, A. W., Bekaert, D., et al. (2018). Tracking the weight of Hurricane Harvey's stormwater using GPS data. Science Advances, 4(9), eaau2477. https://doi.org/10.1126/sciadv.aau2477

Mirwald, A., Cruz-Atienza, V. M., Díaz-Mojica, J., Iglesias, A., Singh, S. K., Villafuerte, C., \& Tago, J. (2019). The 19 September 2017 (M w 7.1) intermediate-depth Mexican earthquake: A slow and energetically inefficient deadly shock. Geophysical Research Letters, 46, 2054-2064. https://doi.org/10.1029/2018GL080904

Murray, K. D., Bekaert, D. P., \& Lohman, R. B. (2019). Tropospheric corrections for InSAR: Statistical assessments and applications to the Central United States and Mexico. Remote Sensing of Environment, 232, 111326. https://doi.org/10.1016/j.rse.2019.111326

Obara, K., \& Hirose, H. (2006). Non-volcanic deep low-frequency tremors accompanying slow slips in the southwest Japan subduction zone. Tectonophysics, 417(1-2), 33-51. https://doi.org/10.1016/j.tecto.2005.04.013

Okada (1992). Internal deformation due to shear and tensile faults in a half space. Bulletin of the Seismological Society of America, 82(2), $1018-1040$ 
Pérez-Campos, X., Kim, Y. H., Husker, A., Davis, P. M., Clayton, R. W., Iglesias, A., et al. (2008). Horizontal subduction and truncation of the Cocos Plate beneath central Mexico. Geophysical Research Letters, 35, L18303. https://doi.org/10.1029/2008GL035127

Pinel-Puysségur, B., Michel, R., \& Avouac, J. P. (2012). Multi-link InSAR time series: Enhancement of a wrapped interferometric database. IEEE Journal of Selected Topics in Applied Earth Observations and Remote Sensing, 5(3), 784-794. https://doi.org/10.1109/JSTARS.2012 2196758

Radiguet, M., Cotton, F., Vergnolle, M., Campillo, M., Valette, B., Kostoglodov, V., \& Cotte, N. (2011). Spatial and temporal evolution of a long term slow slip event: The 2006 Guerrero Slow Slip Event. Geophysical Journal International, 184(2), 816-828. https://doi.org/10. 1111/j.1365-246X.2010.04866.X

Radiguet, M., Cotton, F., Vergnolle, M., Campillo, M., Walpersdorf, A., \& Cotte, N. (2012). Slow slip events and strain accumulation in the Guerrero gap, Mexico. Journal of Geophysical Research, 117, B04305. https://doi.org/10.1029/2011JB008801

Radiguet, M., Cotton, F., Vergnolle, M., Campillo, M., Walpersdorf, A., Cotte, N., \& Kostoglodov, V. (2012). Slow slip events and strain accumulation in the Guerrero gap, Mexico. Journal of Geophysical Research, 117, B04305. https://doi.org/10.1029/2011JB008801

Radiguet, M., Perfettini, H., Cotte, N., Gualandi, A., Valette, B., Kostoglodov, V., et al. (2016). Triggering of the 2014 Mw7.3 Papanoa earthquake by a slow slip event in Guerrero, Mexico. Nature Geoscience, 9(11), 829-833. https://doi.org/10.1038/ngeo2817

Rogers, G., \& Dragert, H. (2003). Episodic tremor and slip on the Cascadia episodic tremor and slip on the Cascadia Subduction Zone: The. Science, 300(2003), 1942-1943. https://doi.org/10.1126/science.1084783

Rosen, P. A., Hensley, S., Peltzer, G., \& Simons, M. (2004). Updated repeat orbit interferometry package released. Eos, 85 , 47.

Rousset, B., Campillo, M., Lasserre, C., Frank, W. B., Cotte, N., Walpersdorf, A., et al. (2017). A geodetic matched-filter search for slow slip with application to the Mexico subduction zone. Journal of Geophysical Research: Solid Earth, 122, 10,498-10,514. https://doi.org/10. 1002/2017JB014448

Rousset, B., Jolivet, R., Simons, M., Lasserre, C., Riel, B., Milillo, P., et al. (2016). An aseismic slip transient on the North Anatolian Fault. Geophysical Research Letters, 43, 3254-3262. https://doi.org/10.1002/2016GL068250

Schwartz, S. Y., \& Rokosky, J. M. (2007). Circum-Pacific subduction zones. Reviews of Geophysics, 45, 1-32. https://doi.org/10.1029/ 2006RG000208.1

Segou, M., \& Parsons, T. (2018). Testing earthquake links in Mexico from 1978 to the 2017 M=8.1 Chiapas and M7.1 Puebla shocks. Geophysical Research Letters, 45, 708-714. https://doi.org/10.1002/2017GL076237

Shirzaei, M., \& Bürgmann, R. (2012). Topography correlated atmospheric delay correction in radar interferometry using wavelet transforms. Geophysical Research Letters, 39, L01305. https://doi.org/10.1029/2011GL049971

Simons, M., \& Rosen, P. A. (2015). Interferometric synthetic aperture radar geodesy (Vol. 3). Oxford: Elsevier B.V. https://doi.org/10.1016/ B978-0-444-53802-4.00061-0

Stone, J. V. (2004). Independent component analysis: A tutorial introduction. Technometrics, 49(3), 357-359. https://doi.org/10.1198/ 004017007000000191

Suárez, G., Santoyo, M. A., Hjorleifsdottir, V., Iglesias, A., Villafuerte, C., \& Cruz-Atienza, V. M. (2019). Large scale lithospheric detachment of the downgoing Cocos plate: The 8 September 2017 earthquake (M w 8.2). Earth and Planetary Science Letters, 509, 9-14. https://doi. org/10.1016/j.epsl.2018.12.018

Tarantola, A. (2005). Inverse problem theory and methods for model parameter estimation. Society for Industrial and Applied Mathematics. UNAM Seismology Group (2015). Papanoa, Mexico earthquake of 18 April 2014 (Mw7.3). Geofisica Internacional, 54, 363-386.

Vergnolle, M., Walpersdorf, A., Kostoglodov, V., Tregoning, P., Santiago, J. A., Cotte, N., \& Franco, S. I. (2010). Slow slip events in Mexico revised from the processing of 11 year GPS observations. Journal of Geophysical Research, 115, B08403. https://doi.org/10.1029/ 2009JB006852

Villafuerte, C., \& Cruz-Atienza, V. M. (2017). Insights into the causal relationship between slow slip and tectonic tremor in Guerrero, Mexico. Journal of Geophysical Research: Solid Earth, 122, 6642-6656. https://doi.org/10.1002/2017JB014037

Wallace, L. M., Hreinsdóttir, S., Ellis, S., Hamling, I., D'Anastasio, E., \& Denys, P. (2018). Triggered slow slip and afterslip on the Southern Hikurangi Subduction Zone following the Kaikura earthquake. Geophysical Research Letters, 45, 4710-4718. https://doi.org/10.1002/ 2018GL077385

Walpersdorf, A., Cotte, N., Kostoglodov, V., Vergnolle, M., Radiguet, M., Santiago, J. A., \& Campillo, M. (2011). Two successive slow slip events evidenced in 2009-2010 by a dense GPS network in Guerrero, Mexico. Geophysical Research Letters, 38, L15307. https://doi.org/ $10.1029 / 2011 \mathrm{GL} 048124$

Walters, R. J., Elliott, J. R., Li, Z., \& Parsons, B. (2013). Rapid strain accumulation on the Ashkabad fault (Turkmenistan) from atmosphere-corrected InSAR. Journal of Geophysical Research: Solid Earth, 118, 3674-3690. https://doi.org/10.1002/jgrb.50236

Williams, S., Bock, Y., \& Fang, P. (1998). Integrated satellite interferometry: Tropospheric noise, GPS estimates and implications for interferometric synthetic aperture radar products. Journal of Geophysical Research, 103(B11), 27,051-27,067. https://doi.org/10.1029/ 98jb02794

Yu, C., Li, Z., Penna, N. T., \& Crippa, P. (2018). Generic atmospheric correction model for interferometric synthetic aperture radar observations. Journal of Geophysical Research: Solid Earth, 123, 9202-9222. https://doi.org/10.1029/2017JB015305

Zebker, H. A., Rosen, P. A., \& Hensley, S. (1997). Atmospheric effects in interferometric synthetic aperture radar surface deformation and topographic maps. Journal of Geophysical Research, 102(10), 7547-7563. https://doi.org/10.1029/96JB03804

Zigone, D., Rivet, D., Radiguet, M., Campillo, M., Voisin, C., Cotte, N., et al. (2012). Triggering of tremors and slow slip event in Guerrero, Mexico, by the $2010 \mathrm{Mw} 8.8$ Maule, Chile, earthquake. Journal of Geophysical Research, 117, B09304. https://doi.org/10.1029/ 2012JB009160 